Silvia Rocha Cangussú

INFECÇÃO NA MONITORAÇÃO INTRAVENTRICULAR DA PRESSÃO INTRACRANIANA COM DRENAGEM CONTÍNUA DO LÍQUIDO CEFALORRAQUIANO

São Paulo 
Silvia Rocha Cangussú

\section{INFECÇÃO NA MONITORAÇÃO INTRAVENTRICULAR DA PRESSÃO INTRACRANIANA COM DRENAGEM CONTÍNUA DO LÍQUIDO CEFALORRAQUIANO}

Dissertação apresentada à Escola de Enfermagem da Universidade de São Paulo, programa Enfermagem na Saúde do Adulto, para a obtenção do título de Mestre em Enfermagem.

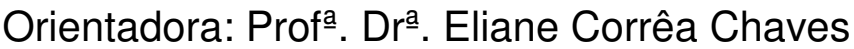

São Paulo 
Catalogação na Publicação (CIP)

Biblioteca "Wanda de Aguiar Horta" da EEUSP

Escola de Enfermagem da Universidade de São Paulo

CANGUSSÚ, Silvia Rocha.

Infecção na monitoração intraventricular da pressão intracraniana com drenagem contínua do líquido cefalorraquiano. / Silvia Rocha Cangussú.

- São Paulo: S.R. Cangussú, 2006.

$94 \mathrm{p}$.

Dissertação (Mestrado) - Escola de Enfermagem da Universidade de São Paulo.

Orientadora: Prof ${ }^{a}$. Dr$^{\mathrm{a}}$. Eliane Corrêa Chaves.

1. Pressão Intracraniana (Monitoração) 2. Ventrículo (Infecção)

3. Procedimentos Neurocirúrgicos (Infecção) I. Título. 
À minha mãe, Cleusa e às eternas, Laika e Sultana, minhas fontes de inspiração. 


\section{Agradecimentos}

O presente estudo é resultado da combinação de desejos e esforços oriundos de diversas fontes que acreditaram na importância de se investigar as infecções proporcionadas ou potencializadas pelo método de monitoração intraventricular da pressão intracraniana com drenagem continua do líquido cefalorraquiano, assim como dos fatores de risco para estas infecções.

Este trabalho não poderia ter sido elaborado sem a imprescindível participação de pessoas que, a despeito do possível sofrimento físico e emocional, participaram deste estudo com tolerância e compreensão. Estes agradecimentos são, acima de tudo, aos pacientes incluídos neste estudo, incluindo aqueles os quais só podemos prestar homenagens póstumas.

Agradeço a colaboração no desenvolvimento deste trabalho:

À Profa. Dra. Eliane Corrêa Chaves, que orientou este estudo acreditando em minha capacidade para realizá-lo e participou assim, ativamente de meu aprimoramento pessoal e profissional.

Ao Prof. Dr. Almir Ferreira de Andrade, por todos os momentos de discussão sobre o tema, pelas críticas, pelas sugestões e por todo apoio dispensado, o qual foi decisivo para a realização deste estudo.

Ao Prof. Dr. Raul Marino Jr., pela confiança em minha capacidade para execução desta pesquisa permitindo a realização desta.

Ao Prof. Dr. Dário Biroline, por todo espaço concedido e suporte necessário para realização deste estudo. 
À Profa. Dra. Rúbia Aparecida Lacerda, pelas sugestões valiosas para o desenvolvimento desta pesquisa.

À equipe médica da neurocirurgia do Hospital das Clínicas da Universidade de São Paulo, por toda colaboração e sugestões.

À equipe médica das UTIs da neurologia e do trauma do Hospital das Clínicas da Universidade de São Paulo, por toda receptividade e colaboração imprescindível para a execução deste trabalho.

À equipe de enfermagem das UTIs da neurologia e do trauma do Hospital das Clínicas da Universidade de São Paulo, por toda compreensão e auxílio.

Ao Dr. Fernando Martim Aliaga Rocabado, por todo apoio e explicações sobre técnica cirúrgica entre outras.

À Enf ${ }^{a}$. Tathiana Thiemi Tomo, pelas traduções de alguns artigos e apoio durante toda a pesquisa.

À Enfạ. Fernanda Oshiro Mori, pela formatação e arte final.

Ao meu querido tio, $\operatorname{Prof}^{\circ}$ Eromar Bomfim Rocha, pelas sugestões na redação final.

À Profá. Dra . Sabina Lea Davidson Gotlieb, ao Prof. Dr. Luiz Roberto Giorgetti de Britto e a todos os professores da pós-graduação da USP, aos quais tive a honra de cursar suas disciplinas.

Aos funcionários da Biblioteca da EEUSP, pela atenção no atendimento. 
Às minhas colegas da pós-graduação, por todo o incentivo, pelos momentos de discussão e troca de informações importantes para a elaboração da pesquisa.

Ao Dr. Tarso Augusto Duenhas Accorsi, por toda compreensão e apoio valiosos para a finalização deste trabalho.

À minha família e amigos, por toda compreensão e incentivo durante toda a pesquisa. 


\section{SUMÁRIO}

\section{Lista de Tabelas}

\section{$\underline{\text { Resumo }}$}

\section{Abstract}

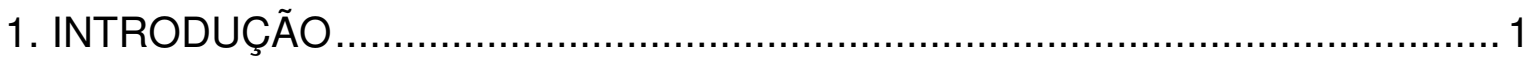

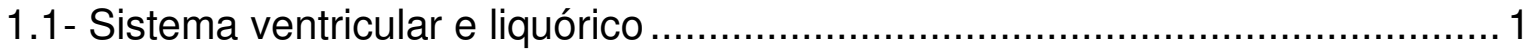

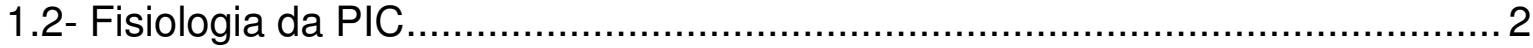

1.3- Histórico da monitoração da PIC .......................................................... 3

1.4- Fatores de risco para ventriculite ...................................................... 6

1.5- Enfermagem na monitoração da PIC .................................................... 11

1.6- Fundamentação do estudo ........................................................... 12

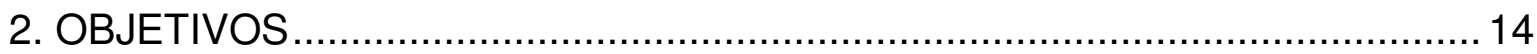

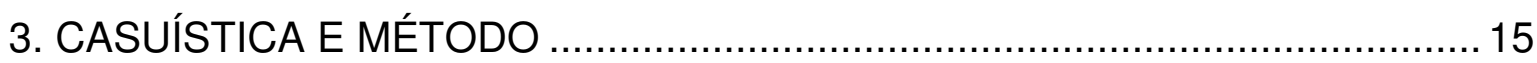

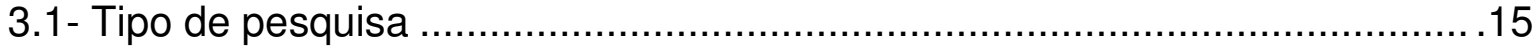

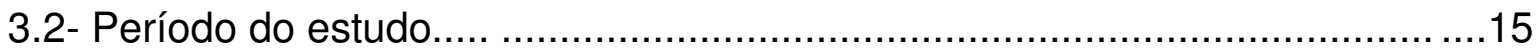

3.3- Caracterização do local e da população..............................................16

3.3.1 - Caracterização do local.............................................................. 16

3.3.2- População de estudo............................................................ 16

3.4- Aspectos éticos e critérios de inclusão ...............................................17

3.4.1- Aspectos éticos............................................................................ 17

3.4.2- Critérios de inclusão ..................................................................

3.5- Definições ...................................................................................... 17

3.5.1- Definição de ventriculite .......................................................... 18

3.5.2- Definição de infecções em sítios extraventriculares ..............................18

3.6- Descrição da técnica de inserção de cateter intraventricular.......................19 


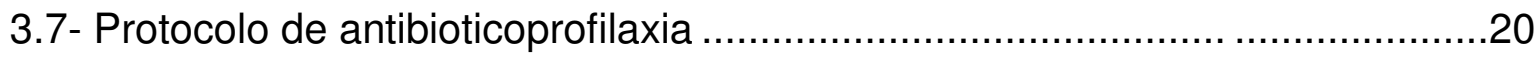

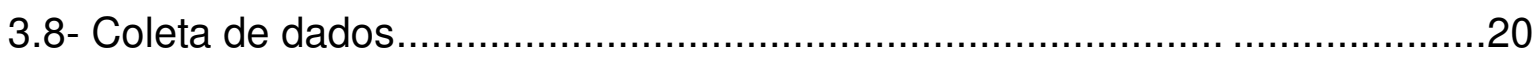

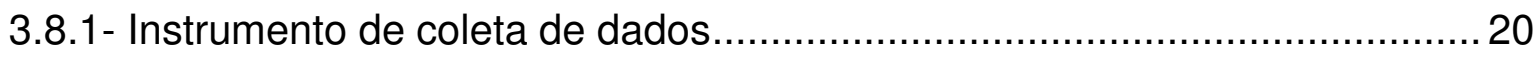

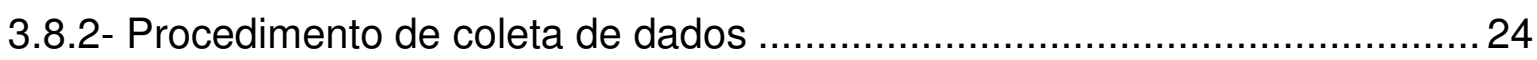

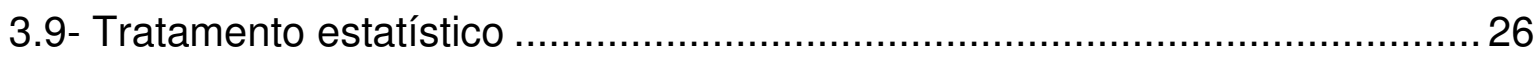

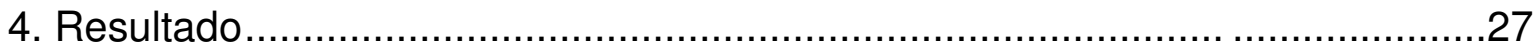

4.1- Dados sobre os pacientes e suas ventriculostomias .................................27

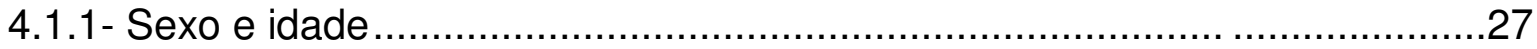

4.1.2- Diagnósticos, terapêutica e evolução ……………………....................28

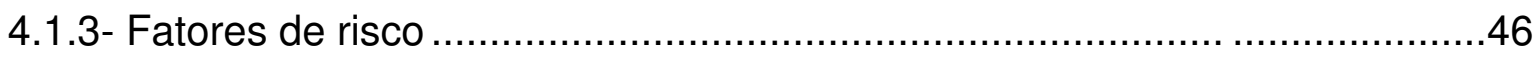

4.2- Relação entre ventriculite, fatores de risco e outras variáveis ......................53

4.2.1- Ventriculite e fatores de risco ..........................................................53

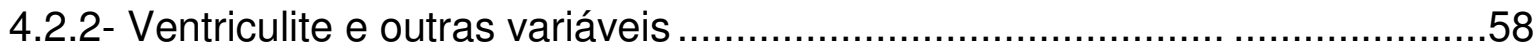

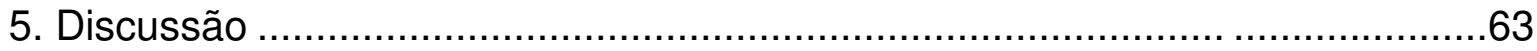

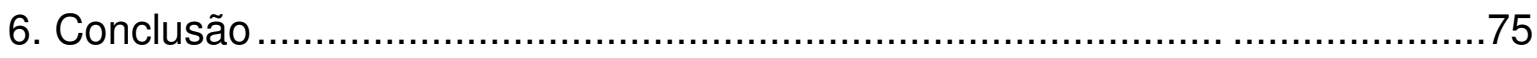

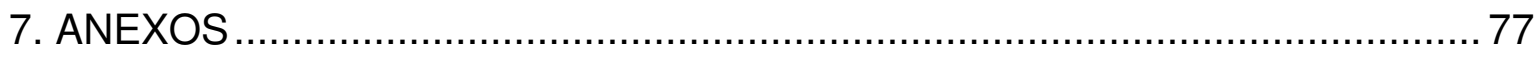

I- Termo de aprovação da Comissão de Ética....................................................77

II- Termo de consentimento livre e esclarecido.................................................. 78

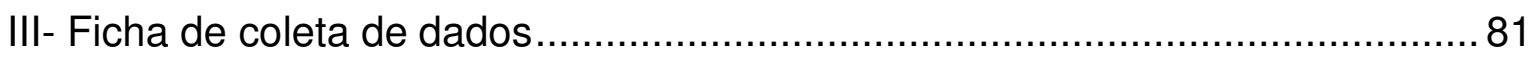

IV- Ficha de manipulações e intercorrências com o sistema de monitoração ....... 85

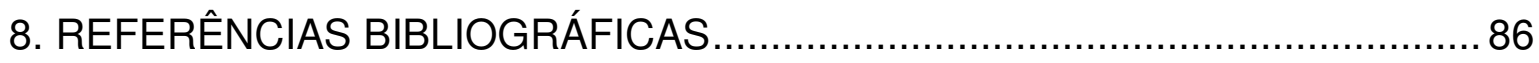




\section{LISTA DE TABELAS}

Tabela 1 - Idade dos pacientes. São Paulo, 2006.

28

Tabela 2 - Distribuição dos sexos nos pacientes. São Paulo, 2006 28

Tabela 3 - Distribuição dos grupos de diagnósticos encontrados nos pacientes. São Paulo, 2006.

Tabela 4 - Diagnósticos mais freqüentes nos pacientes. São Paulo, 2006.

Tabela 5 - Distribuição da quantidade de diagnóstico por pacientes. São Paulo, 2006

Tabela 6 - Procedimentos invasivos na amostra. São Paulo, 2006

Tabela 7 - Tempo de internação dos pacientes no período pré-monitoração. São Paulo, 2006

Tabela 8 - Tempo de permanência da monitoração da PIC nos pacientes. São Paulo, 2006

Tabela 9 - Distribuição do tempo de permanência da monitoração da PIC nos pacientes. São Paulo, 2006

Tabela 10 - Antibióticos profiláticos utilizados nos pacientes. São Paulo, 2006 
Tabela 11 - Distribuição do destino dos pacientes após duas semanas da retirada do cateter de monitoração ou ao final da antibioticoterapia para ventriculite. São Paulo, 2006

Tabela 12 - Escores da Escala de Glasgow no início da internação dos pacientes. São Paulo, 2006.

Tabela 13 - Escores da Escala de Glasgow dos pacientes após duas semanas da retirada do cateter de monitoração ou ao final da antibioticoterapia para ventriculite. São Paulo, 2006.

Tabela 14 - Distribuição da presença de ventriculite nos pacientes. São Paulo, 2006.

Tabela 15 - Momento em relação à monitoração no qual foi diagnosticada ventriculite nos pacientes. São Paulo, 2006 39

Tabela 16 - Distribuição dos dias da constatação da ventriculite nos pacientes sob monitoração da PIC. São Paulo, 2006

Tabela 17 - Distribuição dos dias de constatação da ventriculite nos pacientes após a retirada do cateter de monitoração da PIC. São Paulo, 2006.

Tabela 18 - Distribuição do método de identificação da ventriculite utilizado nos pacientes. São Paulo, 2006 43

Tabela 19 - Agentes causadores de ventriculite nos pacientes. São Paulo, 2006. 
Tabela 20 - Antibióticos utilizados para tratamento da ventriculite nos pacientes. São Paulo, 2006

Tabela 21 - Tempo de utilização da antibioticoterapia nos pacientes com ventriculite. São Paulo, 2006

Tabela 22 - Fatores de risco para ventriculite apresentados pelos pacientes. São Paulo, 2006

Tabela 23 - Permanência da PIC acima de $20 \mathrm{mmHg}$ nos pacientes. São Paulo, 2006

Tabela 24 - Distribuição das culturas positivas de sítios diferentes do ventrículo nos pacientes. São Paulo, 2006

Tabela 25 - Momento em relação à monitoração no qual foi diagnosticada infecção em sitio diferente do ventrículo nos pacientes. São Paulo, 2006

Tabela 26 - Agentes causadores de infecção em sítio diferente do ventrículo nos pacientes. São Paulo, 2006 51

Tabela 27 - Antibióticos utilizados para tratamento de infecção em sítio diferente do ventrículo nos pacientes. São Paulo, 2006

Tabela 28 - Comparação da presença de fatores de risco para ventriculite no grupo de pacientes com ventriculite (GCV) e no grupo sem ventriculite (GSV). São Paulo, 2006 
Tabela 29 - Comparação entre presença dos diagnósticos mais freqüentes no grupo de pacientes com ventriculite (GCV) e no grupo sem ventriculite (GSV). São Paulo, 2006

Tabela 30 - Comparação das estatísticas descritivas relativas à duração da monitoração da PIC no grupo de pacientes GCV e no grupo GSV. São Paulo, 2006

Tabela 31 - Comparação dos períodos de tempo de permanência da monitoração da PIC no grupo de pacientes GCV e no grupo GSV. São Paulo, 2006

Tabela 32 - Comparação das estatísticas descritivas referentes à idade no grupo de pacientes GCV e do GSV. São Paulo, 2006

Tabela 33 - Comparação da distribuição dos sexos no grupo de pacientes GCV e do GSV. São Paulo, 2006

Tabela 34 - Comparação das estatísticas descritivas referentes ao tempo de internação pré-monitoração da PIC no grupo de pacientes GCV e no grupo GSV. São Paulo, 2006

Tabela 35 - Comparação do uso do protocolo de antibioticoprofilaxia nos grupos de pacientes GCV e GSV. São Paulo, 2006

Tabela 36 - Comparação do destino após duas semanas da retirada do cateter de monitoração ou ao final da antibioticoterapia para ventriculite nos grupos de pacientes GCV e do GSV. São Paulo, 2006 
Tabela 37 - Comparação das estatísticas descritivas referentes aos escores da Escala de Glasgow no início da internação no grupo de pacientes GCV e no GSV. São Paulo, 2006.

Tabela 38 - Comparação das estatísticas descritivas referentes aos escores da Escala de Glasgow após duas semanas da retirada do cateter de monitoração ou ao final da antibioticoterapia para ventriculite no grupo de pacientes GCV e GSV. São Paulo, 2006 


\section{RESUMO}

Cangussú SR. Infecção na monitoração intraventricular da pressão intracraniana com drenagem contínua do líquido cefalorraquiano. [dissertação] São Paulo (SP):Escola de Enfermagem da USP;2006.

A monitoração intraventricular da pressão intracraniana (PIC) com drenagem contínua do líquido cefalorraquiano (LCR) já é um procedimento difundido na prática da neurocirurgia e considerado de grande importância diagnóstica, terapêutica e prognóstica por sua precisão. Entretanto, por se tratar de um método invasivo, apresenta riscos potenciais de complicações, sendo a infecção a mais freqüente. O presente estudo teve como objetivo verificar e analisar as taxas de infecções decorrentes deste método de monitoração da PIC, assim como as taxas de seus fatores de risco. As informações obtidas através de prontuários e arquivo dos exames laboratoriais foram registradas em duas fichas de coleta de dados próprias e posteriormente submetidas a testes estatísticos como o de Kruskal-Wallis, de Mann-Whitney, de quiquadrado, teste exato de Fisher e o coeficiente de correlação de Spearman. Obtidas as freqüências relativas e absolutas, médias e desvio-padrão, sendo de $5 \%$ o nível de significância utilizado para os testes. A população deste estudo foi de 79 pacientes dos quais $70.9 \%$ eram do sexo masculino com média de 33.7 anos, sendo que os diagnósticos presentes em $82.3 \%$ eram referentes ao trauma craniencefálico (TCE) seguido de tumores intracranianos e acidentes vasculares cerebrais (AVCs). Todos fizeram uso de antibioticoprofilaxia. A taxa de ventriculite foi de $26.6 \%$, permanecendo o 
cateter, em média, 6.7 dias e apresentando taxas diárias desta infecção variáveis. Não encontramos associação estatisticamente significativa entre tempo de monitoramento e infecção, porém houve um aumento no índice diário de ventriculite após os três primeiros dias e picos no $6^{\circ}, 9^{\circ}$ e $12^{\circ}$ dia indicando uma provável ligação não acumulativa ou linear. Outras variáveis avaliadas neste estudo que apresentaram associação direta com a ocorrência de ventriculite foram o sexo masculino, hemorragia subdural e infecções em outros sítios, principalmente a sepses. Variáveis como idade, procedimentos invasivos, TCE aberto, fístulas liquóricas, hemorragia intraventricular, múltiplas ventriculostomias, presença de PIC acima de $20 \mathrm{mmHg}$, intercorrências durante a cateterização ou manutenção desta não apresentaram associação com a taxa ventriculite, no entanto muitas destas variáveis estiveram presentes em poucos casos dificultando uma conclusão definitiva.

Descritores: monitoração da pressão intracraniana, infecção, ventriculostomia, ventriculite, fatores de risco, epidemiologia, procedimentos neurocirúrgicos. 


\begin{abstract}
Cangussú SR. Infection in the intraventricular monitoring of the intracranial pressure with continuous drainage of cerebrospinal fluid. [dissertation] São Paulo (SP): USP Nursing School; 2006.
\end{abstract}

Intraventricular monitoring of the intracranial pressure (ICP) with continuous drainage of cerebrospinal fluid (CSF) is already a widespread procedure in neurosurgical practice and considered as of great diagnostic, therapeutic and prognostic importance due to its precision. However, as it is an invasive method, it presents a potential risk of complications, the infection being the most frequent. The present study aims at verifying and analyzing the rates of infection originating from this monitoring method of ICP, as well as the rates of its risk factors. The information obtained from case histories and laboratory test files were recorded on two own separate data collection cards and later submitted to statistical tests like the Kruskal-Wallis, Mann-Whitney, ChiSquare, Fisher's exact test, and Spearman correlation coefficients. Relative and absolute, average and standard deviation frequency were verified, $5 \%$ was the significance level utilized for the tests. The population of this study was of 79 patients, $70.9 \%$ of which were male averaging 37.7 years of age, this being so that the diagnostics present in $82.3 \%$ are related to traumatic head injury followed by intracranial tumors and stroke. All of them made use of antibioticprophylaxis. The ventriculitis rate was of $26.6 \%$, the catheter remaining, on average, 6.7 days and showing variable daily rates of this infection. We have not found a statistically meaningful association between 
monitoring time and infection, however there was an increase in the daily ventriculitis rate after the first three days and peaks on the $6^{\text {th }}, 9^{\text {th }}$ and $12^{\text {th }}$ days showing a probable non-cumulative or linear link. Other variables evaluated in this study which presented a direct association with the occurrence of ventriculitis were the male sex, subdural hemorrhage and infections at other sites, mainly sepsis. Variables such as age, invasive procedures, open traumatic head injury, CSF leaks, intraventricular hemorrhage, multiple ventriculostomies, presence of ICP above $20 \mathrm{mmHg}$, intercurrences during catheterization or its maintenance did not show association with the ventriculitis rate, nevertheless many of these variables were present in few cases making a definite conclusion difficult.

Key Words: intracranial pressure monitoring, infection, ventriculostomy, ventriculitis, risk factors, epidemiology, neurosurgical procedures. 


\section{1- INTRODUÇÂO}

A utilização da monitoração da pressão intracraniana (PIC) como instrumento de diagnóstico, tratamento e prognóstico do processo patológico de pacientes com lesões neurológicas traumáticas ou não, tem se tornado cada vez mais difundida dentro da prática da neurocirurgia. As informações geradas por esta monitoração têm permitido auxiliar o tratamento dos pacientes com hipertensão intracraniana ${ }^{1-12}$.

A monitoração intraventricular permite uma medida direta e segura da PIC, através de cateter colocado no ventrículo lateral, direito de preferência, e acoplado a um sistema de medida, usando um transdutor de pressão extracraniano que evita artefatos devidos à movimentação do paciente e permite a recalibração do transdutor a qualquer instante. Outras vantagens do método são: mensuração contínua da PIC e das mudanças dinâmicas que ocorrem dentro do crânio; possibilidade da drenagem do líquido cefalorraquiano (LCR) ventricular, como tratamento imediato das elevações súbitas da PIC, além de permitir análise do material retirado; determinação da complacência intracraniana e inserção de antibióticos diretamente dentro do compartimento onde flui o $\operatorname{LCR}^{13,14}$.

\section{1 - Sistema ventricular e liquórico}

Está situado na intimidade do sistema nervoso central (SNC) e compreende os ventrículos laterais, o terceiro ventrículo e o quarto ventrículo. Os ventrículos laterais comunicam-se com o terceiro ventrículo pelos forames intraventriculares (de Monro). O terceiro e o quarto ventrículos 
são ligados entre si pelo aqueduto cerebral (de Sylvius). Por meio dos orifícios do teto do quarto ventrículo comunica-se o sistema ventricular com o espaço subaraquinóideo. Na parte inferior do quarto ventrículo, inicia-se o canal central da medula, cuja luz é praticamente virtual no homem adulto. Esse canal termina em pequena dilatação situada na extremidade caudal da medula.

As cavidades ventriculares são revestidas pelo epêndima, membrana formada pelas células ependimárias e é também no interior destas cavidades, principalmente nos ventrículos laterais, que se projetam os plexos coróides. Eles são formados por redes vasculares amplamente ramificadas, recobertas pelo epêndima.

O LCR é produzido pelo plexo coróide a uma taxa aproximada de 30ml/hora. O LCR passa dos ventrículos laterais do cérebro para o terceiro ventrículo através do forame de Monro e prossegue até o quarto ventrículo via aqueduto de Sylvius. Ele então sai do sistema ventricular para o espaço subaraquinóideo circundando o cérebro e a medula espinhal. Finalmente ele é reabsorvido para o sistema circulatório venoso por meio de granulações aracnóideas que se projetam no seio sagital superior. A presença de sangue no LCR pode provocar obstrução das granulações araquinóideas, prejudicando a sua reabsorção e produzindo aumento da $\mathrm{PIC}^{15,16}$.

\section{2 - Fisiologia da PIC}

Diferentes processos patológicos que acometem o cérebro podem produzir elevação da PIC. Entretanto, a hipertensão intracraniana pode ter conseqüências que afetam de maneira adversa a função cerebral e, 
conseqüentemente, a evolução do paciente. Portanto, a elevação da PIC não só indica a presença de um problema, mas também pode freqüentemente contribuir para a sua existência.

A PIC normal, em situação de repouso, é de aproximadamente $10 \mathrm{mmHg}$ (136mm de água). Pressões maiores do que $20 \mathrm{mmHg}$ são consideradas francamente anormais e pressões maiores que $40 \mathrm{mmHg}$ são classificadas como graves.

O conceito da Doutrina de Monro-Kellie é de vital importância para a compreensão da dinâmica da PIC. Segundos este conceito, o volume total do conteúdo intracraniano deve permanecer constante, já que o crânio é essencialmente uma caixa não expansível. Sendo assim, se uma massa, tal como um hematoma ou um tumor, for adicionada neste ambiente intracraniano, resultará na saída forçada do crânio de um volume igual de LCR e sangue venoso e a PIC permanecerá com isso normal. Entretanto, quando esses mecanismos de compensação são esgotados, ocorre um aumento exponencial da PIC mesmo para um pequeno aumento no volume do hematoma, por exemplo.

Com isso, uma PIC normal não necessariamente exclui uma lesão em massa, já que ela permanece dentro dos limites normais até que se alcance o ponto de descompensação no momento da exaustão dos seus mecanismos reguladores ${ }^{16}$.

\section{3- Histórico da monitoração da PIC}

Embora a técnica de monitoração contínua da PIC seja relativamente nova, o interesse na fisiopatologia da elevação da PIC vem se estendendo 
há aproximadamente 200 anos. Há mais de um século, a mensuração da PIC era feita indiretamente por punção lombar para sua determinação e análise do $\operatorname{LCR}^{13,17}$.

A mensuração direta da PIC por punção ventricular foi iniciada por Guillaume e Janny ${ }^{18}$, em 1951 na França. O trabalho foi publicado neste mesmo país e teve uma pequena repercussão no exterior. Entretanto, em 1960, Lundberg consolidou o uso desta prática da neurocirurgia, ao publicar sua monografia descrevendo detalhadamente a técnica de punção ventricular, bem como registro preciso e contínuo da PIC e das ondas da PIC durante condições patológicas ou não ${ }^{8,13,14,17-29}$.

Desde então, uma variedade de monitores de PIC foi desenvolvida: dispositivo subaracnóideo ${ }^{30-32}$, cateter subdural ${ }^{33}$, monitor epidural ${ }^{34}$ e intraparenquimatosos, como sendo alternativas para a monitoração ventricular, quando o ventrículo não puder ser puncionado, lembrando que os maiores avanços nesta área se deram nas últimas três décadas, com a procura de um dispositivo ideal, isto é, que fosse confiável, seguro, preciso, de menor custo e, principalmente, que causasse a mínima morbidade nos pacientes ${ }^{1,9,12,17,30,31,35-37 .}$

Historicamente a monitoração da PIC ventricular tem sido usada como um padrão de referência em comparação com a precisão de monitores de PIC em outros compartimentos cerebrais ${ }^{28,}{ }^{38-52}$, além da terapêutica benéfica da drenagem do LCR quando a hipertensão intracraniana estiver vigorando, ou mesmo no momento de PIC normal em que a drenagem for benéfica. Por este motivo, ela continua sendo o método de eleição de muitos neurocirurgiões, pois até mesmo a intraparenquimatosa é tida por alguns 
investigadores como um método que nem sempre corresponde bem aos resultados da intraventricular ${ }^{1,17,41-43,50,53,54}$.

Embora a monitoração da PIC forneça informações importantes para o diagnóstico, tratamento e prognóstico, este procedimento não é isento de riscos. Os maiores riscos estão ligados aos hematomas provocados no ato da inserção do cateter, hemorragias, fístula liquórica, sendo a infecção a complicação mais comum do método ${ }^{1,20,55,56 .}$

Infecção ligada ao sistema ventricular de drenagem contínua foi inicialmente documentada por $\mathrm{Grant}^{57} \mathrm{em}$ 1929. Poppen ${ }^{58}$ relatou ausência de infecção com este mesmo sistema. Bering ${ }^{55}$ constatou que em 29 ventriculostomias três (10.3\%) desenvolveram infecção no LCR com seis dias de monitoração. Lundberg em seu estudo encontrou 13 casos de cultura positiva de bactérias em 105 pacientes ${ }^{14,}$ 59, 60; enquanto outros autores demonstraram em seus estudos $0 \%$ de infecção durante um longo período de monitoração ${ }^{14}$.

Nos últimos 25 anos, vários pesquisadores, enfocando a taxa de infecção e seus fatores de risco com a utilização de monitores ventriculares de PIC, encontraram taxas que variavam, na maioria dos estudos, entre 0 a $27 \%$, apresentando uma média de $10 \%{ }^{14}, 21,59-71$. Por sua vez, outros pesquisadores chegaram a uma taxa de $45 \%$, embora essa taxa ocorresse em menor freqüência ${ }^{1,2,21,35,48,59-67,69,71-74}$. Os tipos de infecção que estão mais freqüentemente associados com a monitoração da PIC intraventicular incluem meningite e ventriculite ${ }^{2}$. 


\section{4 - Fatores de risco para ventriculite}

Os maiores riscos para infecção em ventriculostomias descritos na literatura são: técnica de inserção, sistema de monitoração aberto, procedimentos neurocirúrgicos, duração prolongada da monitoração, cuidados com o cateter (incluindo retirada de amostra de LCR, manipulação do circuito externo, irrigação do sistema), número de monitorações, antibiótico profilaxia, presença de certas condições como hemorragia intraventricular, fístula liquórica, PIC acima de $20 \mathrm{mmHg}$, trauma craniencefálico (TCE) aberto, ambiente físico onde foi colocado o cateter e fatores relacionados ao paciente ${ }^{14,20,29,54,59,61,63,66}$.

A garantia do uso de uma técnica asséptica de inserção do cateter para a prevenção de uma possível contaminação é preconizada por toda a bibliografia consultada, apesar de que alguns estudos prévios demonstram que não há diferença significativa em relação à taxa de infecção, quando se trata do local dentro da instituição onde é inserido o cateter, podendo ser realizado esse procedimento não só na sala cirúrgica, como também dentro da $\mathrm{UTI}^{20,22,61,71}$, sendo descrita sua realização também dentro da sala de emergência, por se tratar de um procedimento simples e urgente nos casos em que a drenagem é necessária ${ }^{53}$.

As características relacionadas ao paciente em alguns estudos indicaram ser um fator de risco, prevalecendo, por exemplo, a incidência de infecção nos pacientes de idade mais avançada ${ }^{66,71}$. O diagnóstico também é associado à incidência de infecção, pois esta prevaleceu, independentemente do número de dias de monitoração, em pacientes que tinham diagnóstico de hemorragia intracerebral com hemorragia 
intraventricular, embora outros diagnósticos não tivessem sido associados. Além disto, esta prevalência também se manteve nos casos em que a PIC chegou a $20 \mathrm{mmHg}$ ou mais ${ }^{61,71,75}$.

Procedimentos neurocirúrgicos associados à colocação de monitores de PIC também foram apresentados como fatores de risco para infecção ${ }^{61}$, 75

O sistema de monitoração aberto para a drenagem é descrito como um fator de risco para esta complicação, sendo recomendado por diversos autores $^{14,20,21,71}$ o uso do sistema fechado com limitadas aberturas, se essas forem necessárias para a drenagem de LCR, introdução de antibióticos e para a coleta de amostra de LCR.

Embora Mayhall et $\mathrm{al}^{61} \mathrm{em}$ seu estudo prospectivo não tenham encontrado associação entre drenagem de LCR e a ocorrência de infecção, estes e outros autores recomendam a limitação do número de irrigações do sistema, pois estas aumentam a colonização bacteriana de $6 \%$ a $19 \%$, fato este observado em estudo prévio ${ }^{59}$. A introdução por toque contaminado e a retrógrada migração de microorganismos pela coluna de fluido, por irrigação, para dentro do ventrículo, iniciando-se assim a introdução das bactérias e o início da infecção, foram descritas em estudos como o de Wyler e Kelly ${ }^{65} \mathrm{e}$ Aucoin et al ${ }^{59}$, chegando a uma taxa de $18,6 \%$ versus $5,7 \%$ de infecção em população que recebeu irrigação e em outra que não recebeu, respectivamente. A presença de fístula liquórica também é um forte fator de risco para infecção $0^{20,21,53}$.

Adicionalmente, pacientes com focos infecciosos em lugares diferentes do SNC, principalmente pneumonias e infecção do trato urinário, 
têm mostrado uma tendência para apresentar ventriculite ou meningite. Em sua pesquisa, Rebuck et $\mathrm{al}^{53}$ encontraram, em $78 \%$ dos pacientes infectados, microorganismos distintos entre culturas de LCR e do sítio específico da infecção.

Entre os estudos que examinam a taxa de infecção entre os pacientes com monitoração de PIC, assim como a função da antibioticoprofilaxia, podemos citar Wyler e Kelly ${ }^{65}$, os quais encontraram em seu estudo retrospectivo uma taxa de $9 \%$ de infecção nos pacientes que receberam antibioticoprofilaxia contra $27 \%$ dos que não receberam, embora os antibióticos tenham sido dados continuamente durante toda a permanência da monitoração. Somente 10\% dos que receberam antibióticos profiláticos, comparados com $18 \%$ dos que não receberam, desenvolveram infecção, nas séries de Stenager et $\mathrm{al}^{64}$. Winfield et $\mathrm{al}^{71}$ também encontraram resultado positivo no uso do tratamento profilático e por isso recomendam seu uso.

Já estudos como o prospectivo de Mayhall et $\mathrm{al}^{61}$, em que houve uso de Nafcilina profilática, não foram encontrados resultados que comprovassem a influência desta na ocorrência de infecção na ventriculostomia.

O efeito profilático dos antibióticos na taxa de infecção causada por

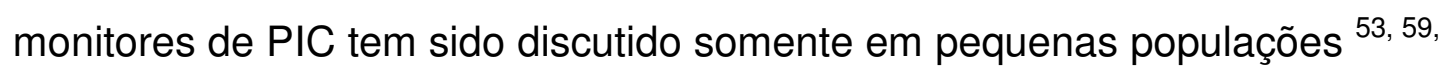
$64,66,69$

Observações feitas por Mayhall et $\mathrm{al}^{61}$ indicaram que 0 risco de iatrogenia por aumento do índice de infecção no SNC com a monitoração da PIC é alto e acumulativo, sendo este índice de $9 \%$ de infecção para o 5 dia 
e 21,37 e $42 \%$ para o $8^{\circ}, 10^{\circ}$ e $11^{\circ}$ dia, respectivamente, embora pacientes monitorados por 3 dias ou menos, não apresentem nenhuma ocorrência de infecção. Com estas observações criou-se um pseudoprotocolo na prática da monitoração da PIC, sendo que tal protocolo consiste na remoção do cateter depois do $5^{\circ}$ dia, e na nova inserção de um novo cateter em outro sítio, se estiver indicada a continuação da monitoração, tendo como base que ventriculostomias prévias não foram associadas com o aumento dos casos de ventriculite ou meningite pela subseqüente cateterização ${ }^{22}$.

Muitos outros investigadores também acharam esta correlação entre infecção e tempo de monitoração. Wyler e Kelly ${ }^{65}$ observaram que pacientes com infecção tinham em média 8.1 dias de monitoração enquanto que pacientes sem infecção tinham 2.5 dias de monitoração. Rosner e Becker ${ }^{66}$ encontraram entre os pacientes com complicações por monitoração um tempo duas vezes maior de monitoração do que entre os pacientes sem complicações que foram monitorados por menos de 4 dias.

Narayan et al $^{1}$ determinaram que 0 mais significativo fator responsável pela infecção por cateter intraventricular é a duração da monitoração. Em sua série, $85 \%$ das infecções ocorreram no $5^{\circ}$ dia ou depois e $15 \%$, no $4^{\circ}$ dia. Nenhuma infecção ocorreu nos pacientes com 3 dias ou menos. Outros autores também confirmaram esta relação ${ }^{17,53,61}$.

Entretanto outras análises, como a de Winfield et $\mathrm{al}^{71}$, demonstraram claramente que o aumento do risco diário de infecção não está associado com a duração da monitoração de PIC, por um período máximo necessário de uma ou duas semanas, nos casos clínicos envolvendo elevação da PIC. E, ao contrário dos estudos relacionados acima, esses autores observaram 
que a rotina de reinserção do cateter, por causa do aumento do risco diário, está associada ao aumento dos custos médicos e expõe o paciente a grandes riscos por complicação de colocação do cateter. Sendo assim, recomendam a não retirada para a nova reinserção do cateter até que haja uma clínica indicando o procedimento e evitando, deste modo, o aumento da taxa de morbidade deste procedimento assim como o dos custos médicos.

Além disto, outros estudos indicam a diminuição da taxa de infecção após os seis primeiros dias, indicando que a infecção é introduzida no momento da inserção do monitor e assim sugerindo que esta taxa pode ser aumentada se a rotina de reinserção após 5 dias for seguida, contradizendo o que Mayhall et $a^{61}$ sugeriram quando encontraram a não associação entre infecção e múltiplas ventriculostomias prévias. Estas contradições já foram motivo de críticas mútuas entre Kanter e Weiner ${ }^{76}$ e Mayhall et al ${ }^{61}$.

Os estudos de Smith e Alksne ${ }^{21}$, que analisaram pacientes tratados com antibioticoprofilaxia, apresentaram uma média de 2.7 dias de monitoração entre os infectados contra 4 dias entre os não infectados, negando assim a relação de tempo e infecção.

Similarmente aos resultados de Kanter e Weiner $^{76}$, Stenager et al ${ }^{64}$ encontraram incidência de infecção mais prevalente nos primeiros dias depois da ventriculostomia, e Ohrstrom at $\mathrm{al}^{77}$ referiram uma taxa de infecção uniforme durante todo o tempo de monitoração nos pacientes com ventriculostomia.

Clark et al ${ }^{69}$ demonstraram a associação entre múltiplas monitorações de PIC e as complicações provenientes destas e encontraram uma taxa $80 \%$ de complicações na 3 ${ }^{\text {a }}$ monitoração comparada com $10.3 \%$ nas primeiras. 
Quarenta e cinco por cento de todas infecções nosocomiais são relacionadas a dispositivos invasivos, sendo que um quarto destas são atribuídas a infusão de fluidos e cateteres de monitoração ${ }^{78}$.

Infecções causam desconfortos e podem atrasar a recuperação do paciente, prolongando a hospitalização e aumentando o custo do tratamento. Uma única infecção pode aumentar os custos hospitalares de 600 a 2.686 dólares e prolongar a hospitalização por aproximadamente 10 dias $^{78,79}$. Uma infecção do SNC pode ser mais devastadora, tendo em vista a ocorrência de possíveis seqüelas que podem incapacitar permanentemente o indivíduo, além do alto índice de mortalidade que provocam ${ }^{80}$.

\section{5 - Enfermagem na monitoração da PIC}

O sucesso da monitoração, com ou sem o benefício da drenagem do LCR e com minimização dos riscos da manutenção deste sistema, depende diretamente da equipe de enfermagem através dos seus cuidados diários ${ }^{72}$. O maior objetivo da enfermagem, no que se refere ao paciente com monitoração de PIC, é a prevenção dos riscos de morbimortalidade proporcionados pelo aumento da $\mathrm{PIC}^{72,81,82}$, sendo que outro importante objetivo é a manutenção do sistema de monitoração da PIC para assegurar uma leitura fidedigna dos dados e a prevenção da infecção relacionada à monitoração ${ }^{20}$. Esses cuidados diários para a manutenção do sistema englobam mais especificamente as seguintes ações, considerando algumas variações destas dependendo de cada instituição: cuidados que garantam um ambiente mais asséptico possível no momento da cateterização; cuidados na assistência ao paciente para não levar patógenos infectantes de 
outros sítios para a ventriculostomia; curativo na inserção do cateter de monitoração de PIC; cuidados com a bolsa coletora de LCR para que não haja uma superdrenagem com colapso do ventrículo, como também fluxo retrógado de LCR ao ventrículo proporcionando maior risco para infecção; esvaziamento da bolsa coletora de LCR; cuidados na coleta de amostras de LCR; calibração e medição da PIC periodicamente; cuidados no manuseio do sistema de monitoração para que não haja desconexões; avaliações periódicas do paciente com ênfase em sinais e sintomas de PIC elevada e infecções no SNC, entre outros.

Todos estes cuidados são fundamentais podendo influenciar nas condutas médicas de retirada ou não do cateter de monitoração, com ou sem recateterização e, assim sendo, determinar os benefícios que o paciente poderia usufruir com conduta mais adequada. Portanto, a enfermagem está diretamente relacionada a praticamente todo o processo de monitoração da PIC e assim ao seu sucesso ou não.

\section{6 - Fundamentação do estudo}

Os vários estudos enfocando a temática da infecção na prática da monitoração intraventricular da PIC apresentam resultados diversos e contraditórios, o que torna difícil a escolha da melhor conduta a ser tomada nos casos de pacientes com tendência a alterações da PIC. Assim sendo, se fazem necessárias mais pesquisas, principalmente no contexto nacional, para que se verifique o real índice de infecção proporcionado pelo método, assim como as taxas dos fatores de risco, para assim podermos prevenir ou minimizar estes, tornando a conduta mais segura. 
Fundamentando-se nestas observações, este estudo teve como objetivo contribuir para sanar as seguintes lacunas de conhecimento sobre $o$ sistema de monitoração intermitente da PIC intraventricular com drenagem contínua do LCR: 
Objetivos 


\section{2- OBJETIVOS}

1- Identificar e analisar as infecções por monitoração intraventricular da PIC com drenagem contínua do LCR com suas caracterizações em pacientes com TCE, tumores intracranianos ou acidentes vasculares cerebrais (AVCs) em unidade de terapia intensiva (UTI);

2- Identificar e analisar os fatores de risco para infecção ligados ao paciente, à introdução do cateter intraventricular e à manutenção da monitoração. 


\section{Casuística e Método}




\section{3- Casuística e Método}

\section{1- Tipo de pesquisa}

O estudo de caráter descritivo e correlacional baseou-se em informações que foram colhidas através de um questionário com dados fornecidos pelo exame do LCR e do prontuário do paciente. A partir deles também foi preenchida uma ficha de manipulações e intercorrências destacando-se o dia, hora e o tipo de manipulação ou intercorrência que ocorreram com o sistema de monitoração, sendo que tanto o questionário quanto a ficha foram preenchidos exclusivamente pela pesquisadora.

\section{2- Período do estudo}

Foram incluídos neste estudo pacientes monitorados de janeiro de 2001 a novembro de 2005 no caso de pacientes com TCE, pois obtivemos uma listagem de todos estes pacientes através de arquivos existente na Instituição. No caso dos pacientes com diagnóstico de tumores intracranianos ou AVCs, não conseguimos esta listagem, motivo pelo qual estes só foram incluídos quando monitorados especificamente durante o período de junho a novembro de 2005.

\section{3- Caracterização do local e da população}

\subsection{1- Caracterização do local}

A pesquisa foi realizada nas UTIs neurocirúrgica e do trauma do Hospital das Clínicas da Faculdade de Medicina da Universidade de São 
Paulo. A escolha do local de estudo baseou-se no fato de nossa atuação profissional no ensino e aprendizado de enfermagem estar intimamente ligada a esse hospital e às pessoas que dele se utilizam. Além disso, o método de monitoração de PIC em questão já é utilizado pela equipe de neurocirurgia dessa instituição sendo que nenhum estudo neste sentido foi realizado ali para verificar a eficácia do método quanto à infecção e fundamentar a utilização desta intervenção.

\subsection{2- População de estudo}

Foram incluídos neste estudo todos os pacientes com TCE internados durante o período de janeiro de 2001 a novembro de 2005. Foram também incluídos os pacientes com diagnósticos de tumores intracranianos ou AVCs, internados durante o período de junho a novembro de 2005 nas UTIs neurocirúrgica e do trauma do Hospital das Clínicas de São Paulo. Em todos os casos, os pacientes só foram incluídos no estudo quando monitorados com o sistema intraventricular de PIC com drenagem contínua do LCR. 


\section{4- Aspectos éticos e critérios de inclusão}

\subsection{1- Aspectos éticos}

A pesquisa só foi realizada após aprovação do Comitê de Ética do Hospital das Clínicas da Faculdade de Medicina da Universidade de São Paulo (Anexo I e II), instituição onde realizamos a pesquisa.

\subsection{2- Critérios de inclusão}

A inclusão dos pacientes foi realizada quando estes, durante 0 período definido do estudo, passaram por monitoramento intraventricular da PIC com drenagem contínua do LCR e durante todo o período de seguimento dos pacientes permaneceram internados nesta Instituição.

Caso um paciente tenha sido transferido para outra instituição durante qualquer momento da monitoração ou nas duas semanas subseqüentes a retirada do cateter ou, ainda antes do término do tratamento para ventriculite, se esta ocorreu, ele foi excluído do estudo.

\section{5 - Definições}

Com o propósito de esclarecer que foram utilizadas bases conceituais para sustentar a categorização dos dados feita posteriormente a sua coleta, apresentamos as definições seguintes. 


\subsection{1 - Definição de ventriculite}

A definição de ventriculite foi adaptada dos guidelines do $\mathrm{CDC}^{83}$, sendo definida por pelo menos um dos dois critérios: presença de um microorganismo isolado na cultura do LCR; e/ou presença de febre $\left(>38^{\circ} \mathrm{C}\right)$ na ausência de outra causa conhecida e adoção de apropriada antibioticoterapia e com as seguintes alterações no exame do LCR aumento dos leucócitos ( $>50 \%$ leucócitos polimorfonucleares), aumento das proteínas e diminuição da glicose $(<15 \mathrm{~g} / \mathrm{dl})$ no $\mathrm{LCR}$ ou detecção de microorganismo no exame bacterioscópico. Os exames de cultura do LCR, quando positivos, foram refeitos com nova amostra. Quando o cateter já havia sido retirado, colheu-se nova amostra por punção lombar. Acreditamos que ventriculites podem ter sido proporcionadas pelo cateter intraventricular, até duas semanas após sua retirada. Por este motivo o seguimento dos pacientes foi realizado até duas semanas pós-retirada do cateter nos pacientes que não apresentaram ventriculite.

\subsection{2 - Definição de infecções em sítios extraventriculares}

Infecções em outros sítios extraventriculares foram definidas como presença de cultura positiva proveniente destes, com sinais e sintomas específicos de infecções deles e febre $\left(>38^{\circ} \mathrm{C}\right)$, com adoção de apropriada antibioticoterapia. 


\section{6- Descrição da técnica de inserção de cateter intraventricular}

Neste estudo todos os pacientes foram cateterizados para monitoração da PIC com drenagem contínua do LCR em centro cirúrgico, como é estabelecido nesta Instituição. Primeiramente fez-se tricotomia total cefálica e posterior assepsia com utilização clorexidina alcoólico após degermante. A seguir fez-se uma trepanação no osso frontal, $1 \mathrm{~cm}$ anterior a sutura coronal, 2 a $3 \mathrm{~cm}$ lateral à linha mediana da sutura sagital. Aberto pequeno orifício na dura-máter, o suficiente para inserir de 5 a $7 \mathrm{~cm}$ um cateter ventricular com auxílio de um mandril, até o ventrículo lateral direito, preferencialmente. Após isto, é retirado o mandril e, se comprovada saída de LCR, a parte distal do cateter é tunelizada abaixo da gálea aproximadamente $4 \mathrm{~cm}$ distante do real local de inserção do cateter. Foi feita a fixação do cateter na gálea para não deslocamento deste e sua conexão a uma torneira ligada a um sistema de drenagem fechado com uma bolsa coletora na outra extremidade e a um transdutor localizado externamente e ligado a um monitor que amplifica e registra a PIC. Para ser calibrado, este transdutor foi zerado no nível do forame de Monro e teve que sê-lo rotineiramente já que o transdutor, por estar externamente colocado e não estar fixo ao ponto zero, não acompanhava as possíveis movimentações da cabeça do paciente, podendo registrar pressões não precisas dos valores reais da PIC. 


\section{7- Protocolo de antibioticoprofilaxia}

Neste serviço, a antibioticoprofilaxia para este tipo de cateter é feita com $1 \mathrm{~g}$ de ceftriaxona de 12 em 12 horas, iniciada entre 2 horas antes da cateterização e o momento dessa e somente finalizada após retirada do cateter.

\section{8- Coleta de dados}

\subsection{1- Instrumento de coleta de dados}

Para a coleta de dados foi utilizada uma ficha específica (Anexo III), que foi testada previamente e preenchida unicamente pela pesquisadora, para preservar a uniformidade dos dados obtidos.

Esta ficha foi dividida em quatro partes: a primeira, destinou-se ao registro dos dados gerais; a segunda, ao registro de informações relacionadas à monitoração da $\mathrm{PIC}$; a terceira foi para o registro de informações referentes à presença de fatores de risco para infecção do SNC; a quarta parte destinou-se ao registro dos dados referentes ao perfil do LCR e das demais culturas microbianas.

Na primeira parte foram incluídos os seguintes itens:

- Identificação, englobando variáveis de caráter biológico que puderam determinar características epidemiologicamente significativas, como sexo e idade;

- Diagnóstico principal, visando obter um perfil epidemiológico dos diferentes tipos de diagnóstico e a presença de infecção causada pela ventriculostomia; 
- Outros procedimentos invasivos, os quais puderam ser de diversas naturezas, como cateterizações, sondagens, cirurgias, drenagens, bem como outros procedimentos que possibilitaram a ocorrência de algum tipo de infecção. Estes procedimentos tiveram que ser realizados durante a internação do paciente sendo duas semanas antes da monitoração, na vigência desta e após duas semanas da retirada do cateter de monitoração;

- Tempo de internação, onde foi registrada a permanência dos pacientes em estudo no hospital antes da monitoração da PIC;

- Destino do paciente após duas semanas de retirada do cateter ou ao final da antibioticoterapia. Este item investigou as três hipóteses possíveis de destino dos pacientes após a retirada do cateter intraventricular ou ao final da antibioticoterapia para ventriculite: alta (quando o paciente foi considerado neurologicamente apto a submeter-se a seguimento na enfermaria), continuação da internação (quando o paciente continuou internado na UTI) e óbito (quando a internação foi interrompida pela morte);

- Escala de Glasgow, neste item foi marcado o escore dado pelo médico ao paciente em três momentos específicos os quais refletem sua evolução: na sua chegada ao hospital, na sua internação na UTI e ao final de duas semanas, após a retirada do cateter ou, em caso de paciente infectado pela cateterização intraventricular, o escore foi o dado ao final do tratamento da infecção;

Com relação à monitoração da PIC, foram incluídas as seguintes variáveis: 
- Tempo de monitoração da PIC: onde foi registrado o período de permanência do sistema de monitoração de PIC no paciente;

- Antibiótico profilático: destinado ao registro não só do uso de antibiótico profilático, mas também à identificação deste, sua posologia e seu início e término;

- Presença de ventriculite: aqui foram registradas informações sobre a presença deste tipo de infecção, anotando em qual dia da monitoração se diagnosticou a infecção, qual seu agente causal, o antibiótico usado para tratamento com seu respectivo início, término e posologia.

Na terceira parte da ficha os itens incluídos como prováveis fatores de risco para infecção causada pelo sistema de monitoração da PIC foram:

- Procedimentos neurocirúrgicos prévios e quais foram estes;

- Ventriculostomias prévias e quantas foram feitas;

- Intercorrências no momento da cateterização do ventrículo e quais foram estas;

- Presença de fístula liquórica;

- Presença de TEC aberto com sua respectiva causa;

- Presença de hemorragia intraventricular;

- PIC acima de $20 \mathrm{mmHg}$ e qual foi o dia de monitoração em que houve este aumento da pressão;

- Presença de infecções em locais diferentes do SNC, qual o local deste foco infeccioso, qual o agente causal, em que dia foi diagnosticada e qual o antibiótico usado no seu tratamento;

- Presença de febre, dia em que ocorreu e qual foi o pico febril. 
A quarta e última parte da ficha de coleta de dados foi destinada para o registro dos dados referentes ao perfil do LCR, apontando a data da coleta da amostra, a qual foi analisada, e o dia em relação à monitoração da $\mathrm{PIC}$ a que estes resultados se referem, sendo que as características avaliadas foram: pressão do LCR (este item foi preenchido diariamente com ou sem coleta de amostra do LCR); volume total da amostra; aspecto e cor; aspecto e cor após centrifugação; índice de cor; número de células; hemácias; linfócitos; reticulomonócitos; plasmócitos; neutrófilos; eosinófilos; basófilos; macrófagos; macrófagos leucocitários; macrófagos hemáticos; macrófagos pigmentados; uréia; proteína total; glicose; cloretos; citologia oncótica; reação de Pandy; lactato; bacterioscopia; cultura geral e outras características analisadas no exame do LCR e relevantes para o diagnóstico de infecção.

Também foram preenchidos os campos sobre outras culturas microbianas, quando estas foram realizadas no período de seguimento do paciente, como sangüínea, urinária e outras.

Também foi utilizada uma ficha de manipulações e intercorrências com o sistema de monitoração de PIC (anexo IV), a qual foi reservada para o registro das possíveis intercorrências e manipulações que este sistema sofreu. Esta ficha foi preenchida através das informações contidas no prontuário.

As manipulações e intercorrências citadas no instrumento são: fechamento do sistema para mensuração da PIC; calibração; infusão de antibióticos; retirada de amostra de LCR; irrigação do sistema; vazamento do sistema; troca da bolsa coletora; manipulação não específica do circuito 
externo; curativo na inserção do cateter e outras que vieram a ocorrer. Estas intercorrências e manipulações foram anotadas todas as vezes em que ocorreram, marcando-se também a data e o período do dia em que ocorreram (manhã, tarde e noite).

\subsection{2- Procedimento de coleta de dados}

Houve dois caminhos distintos para o levantamento dos pacientes incluídos no estudo: o primeiro foi o que incluiu os pacientes com diagnóstico de TCE monitorados com o sistema intraventricular durante o período de janeiro de 2001 a junho de 2005, os quais foram levantados através de uma lista arquivo dos pacientes que foram submetidos a este procedimento durante o período citado. Está lista foi cedida pelo diretor da emergência de neurocirurgia da Instituição onde foi realizada a pesquisa. O segundo caminho foi o que incluiu os pacientes com diagnostico de TCE, tumores intracranianos e AVCs durante o período de junho a novembro de 2005 , os quais foram levantados diariamente pela pesquisadora nas UTIs incluídas no estudo.

Após obter o registro dos pacientes, foi usado seu prontuário para coletar os dados requeridos na ficha de coleta de dados e acessados, através do arquivo informatizado do laboratório desta Instituição, os seus resultados de exames laboratoriais durante todo o período de interesse da pesquisa.

Foram averiguadas informações como sexo, idade, diagnóstico principal e escore da Escala de Glasglow na internação, além de todas as 
informações contidas no prontuário desde duas semanas antes da cateterização do ventrículo ou desde o ínicio da internação (nos casos de internação menor que duas semanas) como: neurocirurgias ou outras cirurgias, procedimentos invasivos como drenagens, cateterizações e sondagens e presença de infecções em qualquer sítio. Até duas semanas após retirada do mesmo ou, nos casos em que ocorreu ventriculite, até o fim do seu tratamento, para obter informações como: presença de ventriculite pós-retirada do cateter de monitoração ou infecções em outros sítios, escore da Escala de Glasgow final e destino do paciente, assegurando-se assim a inclusão de todas as infecção devido à monitoração da PIC.

Os pacientes incluídos no período de junho a novembro de 2005 puderam ser acompanhados também pela observação direta da pesquisadora, a qual passava um período indeterminado diariamente nas UTIs referidas coletando dados como a mensuração da PIC, temperatura, manutenção do sistema e antibioticoterapia.

As amostras de LCR, para exames citológicos, bioquímicos, bacterioscópicos e de cultura de microorganismos, foram coletados pela equipe de neurocirurgia através do sistema de monitoramento e drenagem de LCR após assepsia do hub existente no sistema com álcool a $70^{\circ}$ durante no mínimo 5 minutos, e no momento da cateterização do ventrículo, em dias indeterminados para controle de ventriculite, sem presença obrigatória de sinais ou suspeita de infecção e no momento de sua retirada simultaneamente com o exame de cultura de ponta de cateter. Existiram amostras de LCR de alguns pacientes coletadas por punção lombar após retirada do cateter para detecção de infecção nas duas semanas seguintes à 
retirada do cateter por suspeita de infecção no LCR. Quando isso ocorreu, elas foram incluídas.

As amostras de LCR foram analisadas no próprio laboratório central do Hospital das Clínicas como já é rotina.

Pacientes que tiveram alta da UTI para a enfermaria foram acompanhados igualmente aos que permaneceram na UTI, respeitando o período de acompanhamento para coleta de dados.

\section{9- Tratamento estatístico}

Inicialmente todas as variáveis foram analisadas descritivamente. Para as variáveis quantitativas (idade, glasgow...) a análise foi feita através da observação dos valores mínimos e máximos, do cálculo de médias, desvios-padrão e medianas. Para as variáveis qualitativas (sexo, diagnóstico...) calcularam-se freqüências absolutas e relativas.

Para a análise da hipótese de igualdade entre três grupos utilizou-se o teste não-paramétrico de Kruskal-Wallis ${ }^{84}$ e, para a comparação entre dois grupos, o teste não-paramétrico de Mann-Whitney ${ }^{84}$, pois a suposição de normalidade dos dados foi rejeitada.

Para se testar a homogeneidade dos grupos em relação às proporções foi utilizado o teste qui-quadrado ${ }^{84}$ ou o teste exato de Fisher $^{84}$, que é indicado quando ocorrerem freqüências esperadas menores do que 5.

Para o estudo da correlação entre duas variáveis foi utilizado o coeficiente de correlação de Spearman ${ }^{84}$.

O nível de significância utilizado para os testes foi de $5 \%$. 
Resultado 


\section{4- RESULTADO}

Os resultados obtidos neste estudo foram organizados e serão apresentados na seguinte seqüência:

4.1- Dados sobre os pacientes e suas ventriculostomias:

4.1.1- Sexo e idade;

4.1.2- Diagnósticos, terapêutica e evolução;

4.1.3- Fatores de risco;

4.2- Relação entre ventriculite, fatores de risco e outras variáveis:

4.2.1- Ventriculite e fatores de risco;

4.2.2- Ventriculite e outras variáveis.

\section{1- Dados sobre os pacientes e suas ventriculostomias}

Neste item estão apresentados os relativos a sexo, idade e informações sobre evolução clínica e terapêutica dos pacientes dos pacientes que compuseram a população, assim como os dados referentes às suas ventriculostomias.

\subsection{1- Sexo e idade}

A Tabela 1 mostra a composição da população no que tange à idade. 
Tabela 1 - Idade dos pacientes. São Paulo, 2006.

Pacientes

\section{ESTATÍSTICAS DESCRITIVAS}

$\begin{array}{cccccc}N & \text { Média } & \begin{array}{c}\text { Desvio } \\ \text { Padrão }\end{array} & \text { Mínimo } & \text { Mediana } & \text { Máximo } \\ 79 & 33.7 & 16.9 & 4.0 & 29.0 & 74.0\end{array}$

Podemos verificar que houve, nesta população, uma grande amplitude da faixa etária a qual, variando entre 4 e 74 anos de idade apresentou média de 33.7 anos.

Tabela 2 - Distribuição dos sexos nos pacientes. São Paulo, 2006.

\begin{tabular}{ll}
\hline SEXO & PACIENTES
\end{tabular}

\begin{tabular}{lcc} 
& N & $\%$ \\
\hline Feminino & 23 & 29.1 \\
Masculino & 56 & 70.9 \\
Total & 79 & 100.0
\end{tabular}

Por meio da tabela 2 é possível observar que a população foi predominantemente constituída por homens (70.9\%).

\subsection{2- Diagnósticos, terapêutica e evolução}

As tabelas 3,4 e 5 apresentam os resultados relativos aos diagnósticos que levaram os pacientes à monitoração da PIC. Na Tabela 3 os diagnósticos são apresentados compondo três grandes grupos. Já na Tabela 4 são apresentados apenas os mais freqüentes e desagrupadamente. 
Tabela 3 - Distribuição dos grupos de diagnósticos encontrados nos pacientes. São Paulo, 2006.

\section{GRUPOS de}

DIAGNÓSTICO

$T C E^{\star}$

TUMOR $^{\star \star}$

$A V C^{* * *}$

Total

79

65

11

3

\section{PACIENTES}

N $\%$

82.3

13.9

3.8

* Contendo os diagnósticos: hemorragia subdural, hemorragia subaraquinóidea, swelling, contusão, lesão axonal difusa, hemorragia extradural.

** Contendo os diagnósticos: meningeoma, craniofaringeoma, neurinoma, meduloblastoma, melanoma metastático, ependinoma.

*** Contendo os dignósticos: AVC hemorrágico.

A Tabela 3, nos mostra que a maior parte dos diagnósticos que acometeram os pacientes deste estudo pertenciam ao grupo de TCE (82.3\%). 
Tabela 4 - Diagnósticos mais freqüentes nos pacientes. São Paulo, 2006.

DIAGNÓSTICO $\quad$ PACIENTES

\begin{tabular}{llc} 
& N & $\%$ \\
\hline Swelling & 22 & 27.8 \\
$\begin{array}{l}\text { Hemorragia } \\
\text { Subaraquinóidea }\end{array}$ & 22 & 27.8 \\
Hemorragia Subdural & 21 & 26.6 \\
Contusão & 14 & 17.7 \\
Lesão Axonal Difusa & 12 & 15.2 \\
Hemorragia Extradural & 10 & 12.7
\end{tabular}

Verificamos por meio dos dados da Tabela 5 que o diagnóstico de swelling e hemorragia subaraquinóidea foram os mais freqüentes entre os pacientes estudados (cada um representando 27.8\%), seguidos do diagnóstico de hemorragia subdural (26.6\%). A maioria dos pacientes deste estudo apresentaram mais de um diagnóstico (78.5\%). 
Tabela 5 - Distribuição da quantidade de diagnóstico por pacientes.

São Paulo, 2006.

QUANTIDADE de

DIAGNÓSTICOS

\section{PACIENTES}

N $\%$

17

21.5

17

21.5

3

32

40.5

11

14.0

5

2

2.5

Total

100.0

Por meio da Tabela 5, podemos observar que apenas $21.5 \%$ da população possuía apenas um diagnóstico, sendo que a maioria (57.0\%) possuía três ou mais.

Tabela 6 - Procedimentos invasivos na amostra. São Paulo, 2006.

PROCEDIMENTOS

PACIENTES

INVASIVOS

$\mathbf{N}$

$\%$

Cateter* $^{*}$

79

100.0

Sonda**

79

100.0

Cirurgia***

72

91.1

Dreno****

27

34.2

${ }^{*}$ Contendo cateteres intravenosos.

${ }^{* *}$ Contendo sondas gástricas, entéricas e vesicais.

*** Contendo cirurgias neurológicas, ortopédicas, torácicas, abdominais e outras.

${ }^{* * *}$ Contendo drenos cranianos, torácicos e abdominais. 
Podemos ver por meio da Tabela 6 que todos os sujeitos de pesquisa receberam algum tipo de procedimento invasivo. As sondas e os cateteres estiveram presentes em $100.0 \%$ dos pacientes e as cirurgias foram realizadas em $91.1 \%$ dos pacientes.

Tabela 7 - Tempo de internação dos pacientes no período prémonitoração. São Paulo, 2006.

Pacientes

$\mathrm{N}$

79

$\begin{array}{ll}\text { Média } & \text { Desvio } \\ & \text { Padrão }\end{array}$

1.6

$$
2.9
$$

\section{ESTATÍSTICAS DESCRITIVAS}

Mínimo

0.0
Mediana Máximo

1.0

16.0

De acordo com a Tabela 7, o tempo entre a admissão do paciente no hospital e a colocação do cateter de monitoração da PIC, variou de 0 à 16 dias, tendo sido em média de 1.6 dias. Os pacientes que apresentaram maior tempo médio entre a internação e o início da monitoração foram os acometidos por tumores (3.2 dias) e por AVCs (5.3 dias).

Tabela 8 - Tempo de permanência da monitoração da PIC nos pacientes. São Paulo, 2006.

\section{Pacientes}

N

79
Média

6.7

\section{ESTATÍSTICAS DESCRITIVAS}

$\begin{array}{cccc}\begin{array}{c}\text { Desvio } \\ \text { Padrão }\end{array} & \text { Mínimo } & \text { Mediana } & \text { Máximo } \\ 4.4 & 1.0 & 5.0 & 25.0\end{array}$

A permanência da monitoração da PIC nos pacientes variou de 1 a 25 dias, sendo que a média foi de 6.7 dias. O tempo médio de permanência da 
monitoração nos pacientes portadores de tumores e AVCs foram os mais longos (9.8 e 15.3 dias respectivamente).

A Tabela 9 mostra mais detalhadamente a distribuição do tempo de permanência da monitoração nos pacientes participantes deste estudo. 
Tabela 9 - Distribuição do tempo de permanência da monitoração da PIC nos pacientes. São Paulo, 2006.

\begin{tabular}{|c|c|c|}
\hline $\begin{array}{l}\text { TEMPO de } \\
\text { PERMANÊNCIA da } \\
\text { MONITORAÇÃO da PIC } \\
\text { (em dias) }\end{array}$ & $\mathbf{N}$ & $\%$ \\
\hline 1 & 1 & 1.3 \\
\hline 2 & 2 & 2.5 \\
\hline 3 & 9 & 11.4 \\
\hline 4 & 7 & 8.9 \\
\hline 5 & 24 & 30.4 \\
\hline 6 & 10 & 12.7 \\
\hline 7 & 7 & 8.9 \\
\hline 8 & 4 & 5.1 \\
\hline 9 & 3 & 3.8 \\
\hline 10 & 2 & 2.5 \\
\hline 11 & 1 & 1.3 \\
\hline 12 & 1 & 1.3 \\
\hline 13 & 2 & 2.5 \\
\hline 14 & 1 & 1.3 \\
\hline 17 & 1 & 1.3 \\
\hline 18 & 1 & 1.3 \\
\hline 21 & 2 & 2.5 \\
\hline 25 & 1 & 1.3 \\
\hline Total & 79 & 100.0 \\
\hline
\end{tabular}


Com base na Tabela 9, os tempos mais freqüentes de permanência da monitoração da PIC nos pacientes foram em ordem decrescente 5 dias (em $30.4 \%$ dos pacientes), 6 dias (em 12.7\% dos pacientes) e 3 dias (em $11.4 \%$ dos pacientes). É importante destacar, no entanto que $33.1 \%$ dos pacientes permaneceram monitorados por um período igual ou superior a 7 dias.

Neste estudo todos sujeitos de pesquisa receberam antibiótico profilático, porém apenas $46.8 \%$ destes o receberam de acordo com o protocolo de antibioticoprofilaxia para este tipo de procedimento neurocirúrgico padronizado pela Instituição na qual a pesquisa foi realizada. Os demais $53.2 \%$ ou receberam outro antibiótico (em $5.1 \%$ dos casos), ao invés do padronizado (ceftriaxona), ou receberam mais de um antibiótico (em $45.6 \%$ dos casos), fato observado principalmente nos pacientes com TCE associado aos politraumas.

A Tabela 10 mostra os antibióticos mais freqüentemente usados na profilaxia de ventriculite dos pacientes deste estudo. 
Tabela 10 - Antibióticos profiláticos utilizados nos pacientes. São Paulo, 2006.

\begin{tabular}{lcc}
\hline ANTIBIÓTICO & \multicolumn{2}{c}{ PACIENTES } \\
PROFILÁTICO & $\mathbf{N}$ & $\%$ \\
\hline Ceftriaxona & 75 & 94.9 \\
Clindamicina & 18 & 22.8 \\
Oxacilina & 12 & 15.2 \\
Cefalotina & 7 & 8.9 \\
Vancomicina & 3 & 3.8 \\
Metronidazol & 1 & 1.3 \\
Cefepime & 1 & 1.3
\end{tabular}

Como esperado o antibiótico ceftriaxona padronizado nesta Instituição foi o mais utilizado sozinho ou associado a outros em $94.9 \%$ dos pacientes.

O destino dos pacientes após duas semanas da retirada do cateter de monitoração da PIC (nos casos em que não ocorreu ventriculite) ou após o fim do tratamento da ventriculite (nos casos em que essa esteve presente) esta apresentado na Tabela 11. 
Tabela 11 - Distribuição do destino dos pacientes após duas semanas da retirada do cateter de monitoração ou ao final da antibioticoterapia para ventriculite. São Paulo, 2006.

DESTINO dos

PACIENTES

\begin{tabular}{l|l} 
PACIENTES & N
\end{tabular}

$\begin{array}{lcc}\text { Alta da UTI } & 35 & 44.3 \\ \text { Continuação na UTI } & 30 & 38.0 \\ \text { Óbito } & 14 & 17.7 \\ \text { Total } & 79 & 100.0\end{array}$

A Tabela 11 mostra que a maior parte dos pacientes (44.3\%) teve alta da UTI após duas semanas da retirada do cateter de monitoração ou ao final da antibioticoterapia para ventriculite. É importante destacar também que $38.0 \%$ deles permaneceram na UTI, caracterizando uma necessidade prolongada de cuidados intensivos. O percentual de óbitos também é significativo (17.7\%) especialmente se considerarmos que parte dos pacientes que permaneceram na UTI poderiam ter evoluído para óbito, elevando ainda mais este percentual. 
Tabela 12 - Escores da Escala de Glasgow no início da internação dos pacientes. São Paulo, 2006.

Pacientes

$\mathrm{N}$

79
Média

8.0

\section{ESTATÍSTICAS DESCRITIVAS}

Desvio
Padrão

3.4
Mínimo

3.0
Mediana

7.0
Máximo

15.0

Com podemos ver por meio da Tabela 12 os escores da Escala de Glasgow admissional destes pacientes variava de 3 a 15, apresentando valor médio de 8.

Não foi possível obter os escores da Escala de Glasgow logo pós a colocação do cateter para monitoração da PIC, em razão dos pacientes terem sido sedados, no entanto, foram obtidos os escores da Escala de Glasgow apresentados pelos pacientes após duas semanas da retirada do cateter de monitoração ou ao final da antibioticoterapia para ventriculite os quais são apresentados na Tabela 13.

Tabela 13 - Escores da Escala de Glasgow dos pacientes após duas semanas da retirada do cateter de monitoração ou ao final da antibioticoterapia para ventriculite. São Paulo, 2006.

Pacientes

N

79
Média

11.5

\section{ESTATÍSTICAS DESCRITIVAS}

Desvio Padrão

3.7
Mínimo

3.0
Mediana

Máximo

13.0

15.0

A média dos escores da Escala de Glasgow apresentados pelos sujeitos desta pesquisa após duas semanas da retirada do cateter de 
monitoração ou ao final da antibioticoterapia para ventriculite foi de 11.5 tendo variado o que demonstra uma melhora comparada com a média do escore admissional de 3 a 15 pontos.

Tabela 14 - Distribuição da presença de ventriculite nos pacientes. São Paulo, 2006.

\section{PRESENÇA de} PACIENTES

VENTRICULITE $\mathbf{N}$ $\%$

Sim 21 26.6

Não 58 73.4

Total 79 100.0

A Tabela 14 mostra que $26.6 \%$ dos pacientes evoluíram com ventriculite.

A Tabela 15 traz dados referentes ao período de tempo em que a ventriculite foi diagnosticada.

Tabela 15 - Momento em relação à monitoração no qual foi diagnosticada ventriculite nos pacientes. São Paulo, 2006.

\begin{tabular}{cccccc}
\hline Pacientes & \multicolumn{4}{c}{ ESTATíSTICAS DESCRITIVAS } \\
$\mathrm{N}$ & Média & $\begin{array}{c}\text { Desvio } \\
\text { Padrão }\end{array}$ & Mínimo & Mediana & Máximo \\
\hline 16 & $6.2 \mathrm{dm}^{*}$ & 2.9 & $0.0 \mathrm{dm}^{*}$ & $6.0 \mathrm{dm}^{*}$ & $12.0 \mathrm{dm}^{*}$ \\
5 & $7.4 \mathrm{dr}^{* *}$ & 3.8 & $4.0 \mathrm{dr}^{* *}$ & $6.0 \mathrm{dr}^{* *}$ & $12.0 \mathrm{dr}^{* *}$ \\
& & & & \\
${ }^{*} \mathrm{dm}=$ dias de permanência do cateter de monitoração da PIC. & & \\
${ }^{* *} \mathrm{dr}=$ dias após retirada do cateter de monitoração da PIC.
\end{tabular}


A Tabela 15 mostra que nos 16 pacientes que desenvolveram ventriculite na vigência da monitoração da PIC, esta ocorreu desde o dia da colocação do cateter até $012^{0}$ dia após este evento, tendo sido diagnosticada num tempo médio de 6.2 dias. Nos 5 pacientes que já haviam retirado o cateter quando apresentaram ventriculite, esta foi diagnosticada entre $\circ 4^{\circ}$ e $\circ 12^{\circ}$ dia após o término da monitoração num tempo médio de 7.4 dias após este evento.

A Tabela 16 traz mais detalhadamente a distribuição do dia do diagnóstico de ventriculite entre os pacientes diagnosticados na vigência da presença do cateter. 
Tabela 16 - Distribuição dos dias da constatação da ventriculite nos pacientes sob monitoração da PIC. São Paulo, 2006.

\begin{tabular}{lcc}
\hline $\begin{array}{l}\text { DIA do DIAGNÓSTICO } \\
\text { de VENTRICULITE }\end{array}$ & N & $\%$ \\
\hline $\mathbf{0}$ & 1 & 6.3 \\
$\mathbf{3}$ & 1 & 6.3 \\
$\mathbf{4}$ & 2 & 12.5 \\
$\mathbf{5}$ & 2 & 12.5 \\
$\mathbf{6}$ & 4 & 25.0 \\
$\mathbf{7}$ & 1 & 6.3 \\
$\mathbf{8}$ & 1 & 6.3 \\
$\mathbf{9}$ & 1 & 12.5 \\
$\mathbf{1 0}$ & 2 & 6.3 \\
$\mathbf{1 2}$ & 1 & 6.3 \\
Total & 1 & 100.0
\end{tabular}

É possível observar que houve um aumento linear da freqüência do diagnóstico do diagnóstico de ventriculite nos pacientes do dia da cateterização ventricular até o 6ำ dia de monitoração (25.0\%), momento de ápice desta freqüência totalizando $62.6 \%$ dos casos. Após este período a freqüência foi decrescendo gradativamente sem um padrão regular, talvez em função da quantidade reduzida de sujeitos.

Outra forma de observarmos está possível relação é através da taxa diária de ventriculite. Está taxa foi calculada pela divisão do número de infecções diagnosticadas no dia referido, com o número total de cateteres de 
pacientes sem ventriculite existente no mesmo dia. Assim obtivemos uma taxa diária de infecção no ventriculo de $2.6 \%$ até três dias de monitoração, $6.4 \%$ de 4 a 5 dias, $11.4 \%, 4.2 \%, 5.3 \%, 13.3 \%, 9.1 \%$ nos dias $6,7,8,9$ e 10 respectivamente e ainda $11.1 \%$ no $12^{\circ}$ dia. Observamos desta forma que a taxa diária de infecção deste estudo apresenta alguns picos não sendo acumulativa e linear, sendo nula após o décimo segundo dia até a retirada do último cateter no vigésimo quinto dia, lembrando que neste período foram poucos os pacientes ainda monitorados (apenas oito).

Tabela 17 - Distribuição dos dias de constatação da ventriculite nos pacientes após a retirada do cateter de monitoração da PIC. São Paulo, 2006.

DIA do DIAGNÓTICO de VENTRICULITE

\begin{tabular}{lcc} 
& N & $\%$ \\
\hline 4 & 2 & 40.0 \\
6 & 1 & 20.0 \\
11 & 1 & 20.0 \\
12 & 1 & 20.0 \\
Total & 5 & 100.0
\end{tabular}

A Tabela 17 mostra uma distribuição eqüitativa da constatação de ventriculite neste pacientes. O fato deste grupo ter sido constituído por apenas 5 pacientes, nos impede de ir além deste comentário. 
Tabela 18 - Distribuição do método de identificação da ventriculite utilizado nos pacientes. São Paulo, 2006.

\begin{tabular}{lcc}
\hline $\begin{array}{l}\text { MÉTODO de } \\
\text { IDENTIFICAÇÃO da } \\
\text { VENTRICULITE }\end{array}$ & N & PACIENTES \\
\hline $\begin{array}{l}\text { Cultura Positiva do } \\
\text { LCR }\end{array}$ & 17 & 81.0 \\
$\begin{array}{l}\text { Febre e Alterações } \\
\text { Citológicas e } \\
\begin{array}{l}\text { Bioquímicas no LCR } \\
\text { Total }\end{array}\end{array}$ & 4 & 19.0 \\
& 21 & 100.0
\end{tabular}

Conforme os dados da Tabela 18, a maior parte dos diagnósticos de ventriculite $(81.0 \%)$ resultaram da cultura positiva do LCR. Doze destes casos $(70.6 \%)$, além da cultura positiva apresentaram também febre e outras alterações citológicas e bioquímicas no LCR compatíveis com ventriculite. Apenas $19.0 \%$ das ventriculites foram diagnosticados por meio da presença de febre e alterações citológicas e bioquímicas no LCR compatíveis com ventriculite, porém com ausência de cultura positiva do LCR ou identificação de qualquer outro foco infeccioso. Em quase todos os casos de cultura positiva do LCR (76.5\%) houve repetição deste exame para confirmação do resultado.

Os agentes causadores de ventriculite isolados nas culturas positivas de LCR destes pacientes estão apresentados na Tabela 19. 
Tabela 19 - Agentes causadores de ventriculite nos pacientes. São Paulo, 2006.

AGENTE INFECTANTE

PACIENTES

\begin{tabular}{llc} 
& N & $\%$ \\
\hline $\begin{array}{l}\text { Acinetobacter } \\
\text { baumannii }\end{array}$ & 11 & 64.7 \\
$\begin{array}{l}\text { Staphylococcus } \\
\text { coagulase negativo }\end{array}$ & 7 & 41.2 \\
$\begin{array}{l}\text { Enterococcus faecalis } \\
\text { Cocos gram positivo }\end{array}$ & 2 & 11.8 \\
Klebsiella pneumoniae & 2 & 11.8 \\
Proteus mirabilis & 1 & 5.9 \\
Enterobacter aerogenes & 1 & 5.9 \\
\end{tabular}

O agente causador das ventriculites, nos pacientes estudados, mais freqüentemente isolado em meio de cultura foi o Acinetobacter baumannii presente em $64.7 \%$ das culturas positivas de LCR, seguido pelo Staphylococcus coagulase negativo ( $41.2 \%$ dos casos).

Em $35.3 \%$ das culturas positivas de LCR foi isolado mais de um agente infectante. 
Tabela 20 - Antibióticos utilizados para tratamento da ventriculite nos pacientes. São Paulo, 2006.

\begin{tabular}{lcc}
\hline ANTIBIÓTICO & \multicolumn{2}{c}{ PACIENTES } \\
TERAPÊUTICO & $\mathbf{N}$ & $\%$ \\
\hline Vancomicina & 13 & 61.9 \\
Ceftazidima & 9 & 42.9 \\
Meropenem & 6 & 28.6 \\
Ceftriaxona & 4 & 19.0 \\
Clindamicina & 3 & 14.3 \\
Cefepime & 3 & 14.3 \\
Imipenem & 2 & 9.5 \\
Oxacilina & 2 & 9.5
\end{tabular}

A Tabela 20 mostra que a vancomicina foi o antibiótico mais utilizado para tratamento da ventriculite dos pacientes deste estudo (61.9\%), seguido da ceftazidima (42.9\%).

Em $66.7 \%$ dos casos houve associação de mais de um antibiótico utilizado para este tratamento, sendo que em $33.3 \%$ foram utilizados dois, em $23.8 \%$, três e em $9.5 \%$, quatro antibióticos. 
Tabela 21 - Tempo de utilização da antibioticoterapia nos pacientes com ventriculite. São Paulo, 2006.

Pacientes

N

21
Média

17.4

\section{ESTATÍSTICAS DESCRITIVAS}

$\begin{array}{cccc}\begin{array}{c}\text { Desvio } \\ \text { Padrão }\end{array} & \text { Mínimo } & \text { Mediana } & \text { Máximo } \\ 8.7 & 7.0 & 17.0 & 42.0\end{array}$

Por meio da Tabela 21, vemos que o tempo médio de utilização da antibioticoterapia para tratamento da ventriculite nos pacientes deste estudo foi de 17.4 dias, variando de 7 a 42 dias de tratamento.

\subsection{3- Fatores de risco}

As tabelas que se seguem, da 22 à 27 , trarão resultados relativos aos fatores de risco para ventriculite decorrente da monitoração da PIC presentes nos pacientes deste estudo. 
Tabela 22 - Fatores de risco para ventriculite apresentados pelos pacientes. São Paulo, 2006.

\section{FATORES de RISCO para VENTRICULITE}

$\begin{array}{lcc} & \text { N } & \% \\ \text { Neurocirurgias } & & \\ \text { Presença } & 67 & 84.8 \\ \text { Ausência } & 12 & 15.2\end{array}$

Ventriculostomia prévia

Presença

4

Ausência

5.1

94.9

Intercorrência na

cateterização

Presença

Ausência

Fístula LCR

Presença

Ausência

TCE Aberto

Presença

Hemorragia Intraventricular

Presença

Ausência

PIC acima de $20 \mathrm{mmHg}$

Presença

Infecção em Sítio Diferente do Ventrículo

Presença

Ausência

Intercorrência Durante

Manipulação

Presença 
Por meio da Tabela 22 é possível observar que o fator de risco mais freqüentemente encontrados nos pacientes deste estudo foi a presença de neurocirurgia (84.8\% dos casos), seguida pela presença de hemorragia intraventricular (35.4\% dos casos).

Já os demais fatores de risco - ventriculostomias prévias, intercorrência na cateterização, fístula LCR, TCE aberto, PIC acima de $20 \mathrm{mmHg}$, infecção em sítio diferente do ventrículo, intercorrência durante manipulação - estiveram pouco presentes neste estudo com uma freqüência de $5.1 \%, 2.5 \%, 11.4 \%, 6.3 \%, 13.9 \%, 12.7 \%$ e $8.9 \%$ respectivamente.

As intercorrências na cateterização foram: assepsia rápida e três tentativas seqüências de cateterização ventricular fracassadas. Já as intercorrências durante a manipulação do sistema de monitoração foram: retirada acidental do cateter de monitoramento da PIC (em 3 casos) e desconexões do circuito de monitoramento (em 4 casos).

É importante citar que $92.4 \%$ dos pacientes possuíam pelo menos um fator de risco, $68.4 \%$ pelo menos dois e $38.0 \%$ três ou mais.

Tabela 23 - Permanência da PIC acima de $20 \mathrm{mmHg}$ nos pacientes. São Paulo, 2006.

Pacientes

$\mathrm{N}$

11
Média

6.3

\section{ESTATÍSTICAS DESCRITIVAS}

Desvio Padrão

5.5
Mínimo

2.0

4.0
Máximo

19.0

A PIC acima de $20 \mathrm{mmHg}$ esteve presente em 11(13.9\%) dos 79 pacientes do estudo. Nestes 11 pacientes, conforme mostra a Tabela 23, 
esta PIC elevada vigorou de 2 a 19 dias, apresentando duração média de 6.3 dias.

Tabela 24 - Distribuição das culturas positivas de sítios diferentes do ventrículo nos pacientes. São Paulo, 2006.

CULTURA POSITIVA

PACIENTES

\begin{tabular}{lcc} 
& N & $\%$ \\
\hline Hemocultura & 6 & 60.0 \\
Urocultura & 1 & 10.0 \\
Lavado Brônquico & 1 & 10.0 \\
Swab orofaringeo & 1 & 10.0 \\
Swab da craniotomia & 1 & 10.0 \\
Total & 10 & 100.0
\end{tabular}

Dez (12.6\%) dos 79 pacientes apresentaram cultura positiva em outro sitio que não o ventrículo. Em seis destes dez casos (60.0\%), a cultura positiva resultou da hemocultura, conforme podemos observar por meio da Tabela 24. 
Tabela 25 - Momento em relação à monitoração no qual foi diagnosticada infecção em sitio diferente do ventrículo nos pacientes. São Paulo, 2006.

\begin{tabular}{cccccc}
\hline Pacientes & \multicolumn{4}{c}{ ESTATÍSTICAS DESCRITIVAS } \\
$\mathrm{N}$ & Média & $\begin{array}{c}\text { Desvio } \\
\text { Padrão }\end{array}$ & Mínimo & Mediana & Máximo \\
\hline 5 & $5.0 \mathrm{dm}^{*}$ & 1.9 & $3.0 \mathrm{dm}^{*}$ & $5.0 \mathrm{dm}^{*}$ & $8.0 \mathrm{dm}^{*}$ \\
5 & $4.0 \mathrm{dr}^{* *}$ & 1.9 & $2.0 \mathrm{dr}^{* *}$ & $4.0 \mathrm{dr}^{* *}$ & $7.0 \mathrm{dr}^{* *}$ \\
& & & \\
${ }^{*} \mathrm{dm}=$ dias de permanência do cateter de monitoração da PIC. & & \\
${ }^{* *} \mathrm{dr}=$ dias após retirada do cateter de monitoração da PIC.
\end{tabular}

A Tabela 25 mostra que o diagnóstico de infecção em outro sítio diferente do ventrículo nos 5 pacientes (50.0\% dos pacientes infectados em outro sitio) os quais a desenvolveram na vigência da monitoração, foi realizado entre $03^{\circ}$ e $8^{\circ}$ dia, numa média de 5 dias após colocação do cateter. Nos 5 pacientes restantes - também infectados em outros sítios, porém já sem o cateter de monitoração da PIC - a identificação da infecção em outro sitio ocorreu do $2^{\circ}$ ao $7^{\circ}$ dia após retirada do cateter, numa média de 4 dias. 
Tabela 26 - Agentes causadores de infecção em sítio diferente do ventrículo nos pacientes. São Paulo, 2006.

\begin{tabular}{ll}
\hline AGENTE INFECTANTE & PACIENTES
\end{tabular}

\begin{tabular}{lll} 
& N & $\%$ \\
\hline $\begin{array}{l}\text { Acinetobacter } \\
\text { baumannii }\end{array}$ Staphylococcus aureus & 4 & 40.0 \\
Enterococcus faecalis & 2 & 20.0 \\
Klebsiella pneumoniae & 2 & 20.0 \\
Cândida & 2 & 20.0 \\
Enterobacter aerogenes & 1 & 10.0 \\
Trichosporon & 1 & 10.0
\end{tabular}

Como mostra a Tabela 26, os agentes infectantes de outros sítios diferentes do ventrículo foram em ordem decrescente de freqüência o Acinetobacter baumannii (presente em $40.0 \%$ dos casos) seguido pelo Staphylococcus aureus (20.0\% dos casos) e pelo Enterococcus faecalis (20.0\% dos casos).

É interessante destacar que os quatro agentes infectantes mais freqüentes nos sítios não ventriculares coincidiram com os quatro mais freqüentes encontradas nas infecções ventriculares deste estudo (vide tabela 19). Por outro lado, em apenas dois pacientes houve coincidência em relação ao agente infectante no ventrículo e em outro sitio que não este. Num terceiro paciente houve coincidência quanto a um agente infectante, porém na cultura do LCR houve crescimento de um segundo agente não presente no outro foco infeccioso. 
Somente um paciente infectado em outro sítio, durante o período de seguimento dos pacientes, não desenvolveu ventriculite. Nos demais seis casos, os agentes isolados nas culturas de outros sítios foram distintos dos isolados em LCR.

Tabela 27 - Antibióticos utilizados para tratamento de infecção em sítio diferente do ventrículo nos pacientes. São Paulo, 2006.

\begin{tabular}{lcc}
\hline ANTIBIÓTICO & PACIENTES \\
TERAPÊUTICO & N & $\%$ \\
\hline Vancomicina & 6 & 60.0 \\
Ceftriaxona & 3 & 30.0 \\
Cefepime & 3 & 30.0 \\
Clindamicina & 2 & 20.0 \\
Meropenem & 2 & 20.0 \\
Imipenem & 1 & 10.0 \\
Fortaz & 1 & 10.0 \\
Metronidazol & 1 & 10.0
\end{tabular}

Assim como nos casos de ventriculite, as infecções em outros sítios que não o ventrículo também foram tratadas com vancomicina na maioria dos casos (60.0\%), seguida da ceftriaxona (30.0\%) e cefepime (30.0\%) como está mostrado na Tabela 27. Alguns destes casos foram tratados com mais de um antibiótico. 


\section{2- Relação entre ventriculite, fatores de risco e outras variáveis}

A relação entre ventriculite, fatores de risco e outras variáveis serão abordadas neste segundo item. Com esta finalidade, os pacientes deste estudo foram divididos em dois grupos: o grupo que apresentou ventriculite (GCV) e o grupo que não apresentou ventriculite (GSV). Assim sendo, por

meio das tabelas que se seguem serão mostrados os resultados do comportamento de cada variável em relação aos dois grupos separadamente e subseqüente comparação entre ambos.

\subsection{1- Ventriculite e fatores de risco}

As tabelas 28 a 31 apresentaram resultados relativos ao comportamento das variáveis consideradas fatores de risco para ventriculite nos dois grupos em questão (GCV e GSV), comparando-os entre si. 
Tabela 28 - Comparação da presença de fatores de risco para ventriculite no grupo de pacientes com ventriculite (GCV) e no grupo sem ventriculite (GSV). São Paulo, 2006.

$\begin{array}{lccc}\begin{array}{l}\text { FATORES de RISCO para } \\ \text { VENTRICULITE }\end{array} & \text { GCV (n=21) } & \text { GSV (n=58) } & \begin{array}{c}\text { Significância } \\ \left({ }^{*} \mathbf{P}\right)\end{array} \\ \begin{array}{l}\text { Neurocirurgia } \\ \text { Presença }\end{array} & & & \\ \text { Ausência } & 19(90.5 \%) & 48(82.8 \%) & \begin{array}{c}\text { Teste exato de } \\ \text { Fisher }\end{array} \\ & 2(9.5 \%) & 10(17.2 \%) & 0.499 \\ \begin{array}{l}\text { Ventriculostomia prévia } \\ \text { Presença }\end{array} & & & \\ \text { Ausência } & 0(0.0 \%) & 4(6.9 \%) & \begin{array}{c}\text { Teste exato de } \\ \text { Fisher }\end{array} \\ & 21(100.0 \%) & 54(93.1 \%) & 0.569\end{array}$

Intercorrência na

cateterização

Presença

Ausência

$\begin{array}{ccc}0(0.0 \%) & 2(3.5 \%) & \text { Teste exato de } \\ 21(100.0 \%) & 56(96.5 \%) & \text { Fisher } \\ & & 1.000\end{array}$

Fístula LCR

Presença

Ausência

$\begin{array}{ccc}3(14.3 \%) & 6(10.3 \%) & \text { Teste exato de } \\ 18(85.7 \%) & 52(89.7 \%) & \text { Fisher } \\ & & 0.693\end{array}$

TCE Aberto

Presença

Ausência

$\begin{array}{ccc}1(4.8 \%) & 4(6.9 \%) & \text { Teste exato de } \\ 20(95.2 \%) & 54(93.1 \%) & \text { Fisher } \\ & & 1.000\end{array}$

Hemorragia

Intraventricular

Presença

Ausência

$\begin{array}{ccc}4(19.1 \%) & 24(41.4 \%) & \text { Teste exato de } \\ 17(80.9 \%) & 34(58.6 \%) & \text { Fisher } \\ & & 0.067\end{array}$

PIC acima de $20 \mathrm{mmHg}$

Presença

Ausência

$\begin{array}{ccc}3(14.3 \%) & 8(13.8 \%) & \text { Teste exato de } \\ 18(85.7 \%) & 50(86.2 \%) & \text { Fisher } \\ & & 1.000\end{array}$

Infecção em Sítio

Diferente do Ventrículo

Presença

Ausência

$\begin{array}{cc}9(42.9 \%) & 1(1.7 \%) \\ 12(57.1 \%) & 57(98.3 \%)\end{array}$

Teste exato de Fisher $<0.001$

Intercorrência Durante Manipulação

Presença

Ausência

$\begin{array}{cc}2(9.5 \%) & 5(8.6 \%) \\ 19(90.5 \%) & 53(91.4 \%)\end{array}$

Teste exato de Fisher 1.000

${ }^{*} P<0.05$ - estatisticamente significativo 
Observa-se pela Tabela 28 uma diferença estatisticamente significativa no que se refere à infecção em sitio diferente do ventrículo durante o período de seguimento dos pacientes pela pesquisa, nove dos dez casos destas infecções ocorreram no grupo com ventriculite. Os demais fatores de risco para ventriculite não apresentaram diferença estatisticamente significativa entre os grupos GCV e GSV.

Na Tabela 29 podemos ver os diagnósticos mais freqüentes neste estudo, no grupo GCV e GSV, já que este pode ser também um fator de risco para a infecção do ventrículo. 
Tabela 29 - Comparação entre presença dos diagnósticos mais freqüentes no grupo de pacientes com ventriculite (GCV) e no grupo sem ventriculite (GSV). São Paulo, 2006.

DIAGNÒSTICOS

Lesão difusa

Presença

Ausência

Swelling

Presença

Ausência

Hemorragia subdural

Presença

Ausência

Hemorragia meníngea

Presença

Ausência

Contusão

Presença

Ausência

\section{Lesão axonal difusa}

Presença

Ausência

Hemorragia extradural

Presença

Ausência
GCV ( $n=21) \quad$ GSV $(n=58)$

$20(95.2 \%)$

$1(4.8 \%)$

$44(75.9 \%)$

$14(24.1 \%)$

$8(38.1 \%) \quad 14(24.1 \%)$

$13(61.9 \%) \quad 44(75.9 \%)$

$10(47.6 \%) \quad 11(19.0 \%)$

$11(52.4 \%) \quad 47(81.0 \%)$

$5(23.8 \%)$

$16(76.2 \%)$

$11(19.0 \%)$
$47(81.0 \%)$

$3(14.29 \%) \quad 11(19.0 \%)$

$18(85.7 \%) \quad 47(81.0 \%)$

$4(19.0 \%) \quad 8(13.8 \%)$

$17(81.0 \%)$

$50(86.2 \%)$

$5(23.8 \%)$

$16(76.2 \%)$
$5(8.6 \%)$
$53(91.4 \%)$

\section{Significância}

(*P)

Teste exato de

Fisher

0.059

Teste exato de

Fisher

0.221

Teste exato de

Fisher

$0.011^{*}$

Teste exato de

Fisher

0.753

Teste exato de

Fisher

0.749

Teste exato de

Fisher

0.723

Teste exato de

Fisher

0.120

${ }^{\star} P<0.05-$ estatisticamente significativo

Com base na Tabela 29, podemos observar que a hemorragia subdural foi o único diagnóstico estatisticamente mais freqüente entre os pacientes que apresentaram ventriculite. A freqüência dos demais diagnósticos não apresentaram diferença estatisticamente significativa entre os dois grupos. 
Tabela 30 - Comparação das estatísticas descritivas relativas à duração da monitoração da PIC no grupo de pacientes GCV e no grupo GSV. São Paulo, 2006.

\begin{tabular}{cccccccc}
\hline Grupos & Pacientes & \multicolumn{7}{c}{ ESTATístICAS DESCRITIVAS } & \\
& $\mathrm{N}$ & Média & $\begin{array}{c}\text { Desvio } \\
\text { Padrão }\end{array}$ & Mínimo & Mediana & Máximo & $\begin{array}{c}\text { Mann- } \\
\text { Whitney } \\
\left({ }^{*} P\right)\end{array}$ \\
\hline GSV & 58 & 6.9 & 5.0 & 1.0 & 5.0 & 25.0 & 0.337 \\
GCV & 21 & 6.4 & 2.4 & 3.0 & 6.0 & 12.0 & \\
${ }^{*} P<0.05-$ estatisticamente significativo & & & & &
\end{tabular}

O tempo de monitoração da PIC também sendo um potencial fator de risco para ventriculite é apresentado com suas estatísticas descritivas nos grupos na Tabela 30. Ela nos mostra que não houve diferença estatisticamente significativa entre as médias de dias de duração da monitoração da PIC nos dois grupos em questão.

Tabela 31 - Comparação dos períodos de tempo de permanência da monitoração da PIC no grupo de pacientes GCV e no grupo GSV. São Paulo, 2006.

$\begin{array}{lccc}\begin{array}{l}\text { PERÍODO DE } \\ \text { TEMPO }\end{array} & \text { GCV } & \text { GSV } & \begin{array}{c}\text { Teste exato de } \\ \text { Fisher } \\ \left({ }^{*} P\right)\end{array} \\ <3 & 0(0.0 \%) & 3(5.2 \%) & \\ 3-5 & 8(38.1 \%) & 32(55.1 \%) & 0.185 \\ >5 & 13(61.9 \%) & 23(39.7 \%) & \\ \text { Total } & 21(100.0 \%) & 58(100.0 \%) & \\ { }^{*} P<0.05-\text { estatisticamente significativo } & & \end{array}$


Mais uma vez, por meio da Tabela 31, verifica-se que não houve diferença estatisticamente significativa em relação ao tempo de permanência da monitoração da PIC nos dois grupos estudados.

\subsection{2- Ventriculite e outras variáveis}

As tabelas 32 a 38 trazem resultados referentes à comparação do comportamento de variáveis que poderiam influir na vulnerabilidade à ventriculite nos dois grupos aqui estudados (GCV e GSV).

Tabela 32 - Comparação das estatísticas descritivas referentes à idade no grupo de pacientes GCV e do GSV. São Paulo, 2006.

\begin{tabular}{cccccccc}
\hline Grupos & Pacientes & \multicolumn{6}{c}{ ESTATíSTICAS DESCRITIVAS } \\
& $\mathrm{N}$ & Média & $\begin{array}{c}\text { Desvio } \\
\text { Padrão }\end{array}$ & Mínimo & Mediana & Máximo & $\begin{array}{c}\text { Mann- } \\
\text { Whitney } \\
\left({ }^{*} P\right)\end{array}$ \\
\hline GSV & 58 & 35.3 & 17.9 & 8.0 & 30.0 & 74.0 & 0.312 \\
GCV & 21 & 29.3 & 13.3 & 4.0 & 28.0 & 63.0 & \\
${ }^{*} P<0.05$ - estatisticamente significativo & & & & & &
\end{tabular}

A Tabela 32 mostra que não houve diferença estatisticamente significativa entre a média de idade do grupo GSV e do grupo GCV. 
Tabela 33 - Comparação da distribuição dos sexos no grupo de pacientes GCV e do GSV. São Paulo, 2006.

\begin{tabular}{lccc}
\multicolumn{1}{c}{ SEXO } & GCV & GSV & $\begin{array}{c}\text { Teste exato de } \\
\text { Fisher } \\
\left({ }^{*} P\right)\end{array}$ \\
Masculino & $21(100.0 \%)$ & $35(60.3 \%)$ & $\mathbf{0 . 0 0 1}$ \\
Feminino & $0(0.0 \%)$ & $23(39.7 \%)$ & \\
Total & $21(100.0 \%)$ & $58(100.0 \%)$ & \\
${ }^{*} P<0.05-$ estatisticamente significativo & &
\end{tabular}

Por meio da Tabela 33 é possível observar que o grupo de pacientes GCV possuía mais homens do que o grupo GSV sendo que esta diferença foi estatisticamente significativa, apontando uma associação entre o sexo masculino e ventriculite, neste estudo.

Tabela 34 - Comparação das estatísticas descritivas referentes ao tempo de internação pré-monitoração da PIC no grupo de pacientes GCV e no grupo GSV. São Paulo, 2006.

\begin{tabular}{cccccccc}
\hline Grupos & Pacientes & \multicolumn{6}{c}{ ESTATístICAS DESCRITIVAS } \\
& $\mathrm{N}$ & Média & $\begin{array}{c}\text { Desvio } \\
\text { Padrão }\end{array}$ & Mínimo & Mediana & Máximo & $\begin{array}{c}\text { Mann- } \\
\text { Whitney } \\
\left({ }^{*} P\right)\end{array}$ \\
\hline GSV & 58 & 1.8 & 3.2 & 0 & 1.0 & 16.0 & 0.626 \\
GCV & 21 & 0.9 & 1.4 & 0 & 1.0 & 6.0 & \\
${ }^{*} P<0.05-$ estatisticamente significativo & & & & &
\end{tabular}


Como se observa por meio da Tabela 34 não temos uma diferença estatisticamente significativa entre os grupos em relação à média dos dias anteriores à monitoração nos dois grupos estudados.

Tabela 35 - Comparação do uso do protocolo de antibioticoprofilaxia nos grupos de pacientes GCV e GSV. São Paulo, 2006.

$\begin{array}{lccc}\text { USO do PROTOCOLO de } & \text { GCV } & \text { GSV } & \begin{array}{c}\text { Qui-quadrado } \\ \left({ }^{\star} P\right)\end{array} \\ \begin{array}{l}\text { ANTIBIOTICOPROFILAXIA } \\ \text { Sim }\end{array} & 8(38.1 \%) & 29(50.0 \%) & 0.349 \\ \text { Não } & 13(61.9 \%) & 29(50.0 \%) & \\ \text { Total } & 21(100.0 \%) & 58(100.0 \%) & \end{array}$

${ }^{*} P<0.05$ - estatisticamente significativo

A Tabela 35 mostra que não houve diferença estatisticamente significativa entre os grupos deste estudo em relação ao uso do protocolo de antibioticoprofilaxia.

Tabela 36 - Comparação do destino após duas semanas da retirada do cateter de monitoração ou ao final da antibioticoterapia para ventriculite nos grupos de pacientes GCV e do GSV. São Paulo, 2006.

DESTINO GCV

Alta $10(47.6 \%)$

GSV

$25(43.1 \%)$

Continuação

Óbito

Total

$$
\text { na }
$$$$
9(42.9 \%)
$$$$
2(9.5 \%)
$$

$21(36.2 \%)$

$12(20.7 \%)$

$58(100.0 \%)$

${ }^{*} P<0.05$ - estatisticamente significativo

Qui-quadrado

0.513 
Não houve diferença estatisticamente significativa nos destinos dos pacientes que compunham os grupos GCV e GSV, conforme se observa na Tabela 36 .

Tabela 37 - Comparação das estatísticas descritivas referentes aos escores da Escala de Glasgow no início da internação no grupo de pacientes GCV e no GSV. São Paulo, 2006.

\begin{tabular}{cccccccc} 
Grupos & Pacientes & \multicolumn{6}{c}{ ESTATíSTICAS DESCRITIVAS } \\
N & Média & $\begin{array}{c}\text { Desvio } \\
\text { Padrão }\end{array}$ & Mínimo & Mediana & Máximo & $\begin{array}{c}\text { Mann- } \\
\text { Whitney } \\
\left({ }^{*} P\right)\end{array}$ \\
\hline GSV & 58 & 8.4 & 3.7 & 3.0 & 7.0 & 15.0 & 0.204 \\
GCV & 21 & 6.8 & 2.1 & 4.0 & 6.0 & 12.0 & \\
${ }^{*} P<0.05$ - estatisticamente significativo & & & & &
\end{tabular}

Conforme Tabela 37, não houve diferença estatisticamente significativa entre as médias dos escores da Escala de Glasgow no início da internação nos dois grupos em questão. 
Tabela 38 - Comparação das estatísticas descritivas referentes aos escores da Escala de Glasgow após duas semanas da retirada do cateter de monitoração ou ao final da antibioticoterapia para ventriculite no grupo de pacientes GCV e GSV. São Paulo, 2006.

\begin{tabular}{cccccccc}
\hline Grupos & Pacientes & \multicolumn{6}{c}{ ESTATíSTICAS DESCRITIVAS } \\
& $\mathrm{N}$ & Média & $\begin{array}{c}\text { Desvio } \\
\text { Padrão }\end{array}$ & Mínimo & Mediana & Máximo & $\begin{array}{c}\text { Mann- } \\
\text { Whitney } \\
\left({ }^{*} P\right)\end{array}$ \\
\hline GSV & 58 & 11.5 & 3.7 & 3.0 & 13.0 & 15.0 & 0.564 \\
GCV & 21 & 11.6 & 3.2 & 4.0 & 13.0 & 15.0 & \\
${ }^{*} P<0.05$ - estatisticamente significativo & & & & &
\end{tabular}

Não houve diferença estatisticamente significativa ao se comparar as médias dos escores da Escala de Glasgow após duas semanas da retirada do cateter de monitoração do grupo GSV ou ao final da antibioticoterapia para ventriculite do grupo GCV, conforme mostra a Tabela 38. 
Discussão 


\section{5- DISCUSSÃO}

Conforme apresentado anteriormente, a população deste estudo foi composta por 79 pacientes. Destes, $70.9 \%$ eram homens e apresentavam idade média de 33.7 anos. Estes resultados parecem estar relacionados ao fato de que $82.3 \%$ deles eram vítimas de TCE (principalmente hemorragia subdural, hemorragia subaraquinóidea, swelling, contusão, lesão axonal difusa e hemorragia extradural), pois segundo mostram estudos epidemiológicos, homens em idade jovem são as vítimas mais freqüentes de acidentes ou outras causas que podem resultar em TCE ${ }^{85-89}$.

78.5\% dos pacientes apresentaram dois ou mais diagnósticos associados, mostrando a complexidade e a gravidade do processo mórbido destes. Todos os pacientes foram submetidos a tomografia computadorizada (TC) de crânio e somente os que possuíam lesão difusa tipo III e IV, segundo critério de Marshall et $\mathrm{al}^{90}$, foram monitorados.

O escore da escala de coma de Glasgow (ECG) no momento da internação obteve a média de 8 pontos, corroborando mais uma vez os dados que indicam a gravidade dos casos. No estudo realizado por Dantas Filho et $\mathrm{al}^{85}$, concluiu-se que a manifestação clínica inicial, medida através da ECG, foi um forte indicador da gravidade das lesões neurológicas e também do prognóstico nas doenças traumáticas e não-traumáticas.

O baixo valor médio dos escores de ECG obtidos neste estudo pode também estar relacionado à alta freqüência de diagnósticos ligados ao trauma nesta população, uma vez que, apenas vítimas de traumas graves (ECG de 8 a 3 pontos), moderados (ECG de 13 a 9 pontos) e leves 
sintomáticos passaram por TC de crânio, conforme protocolo de tratamento do trauma craniencefálico ${ }^{91}$ e de acordo com o resultado deste exame obtiveram a indicação da monitoração da PIC com drenagem contínua do LCR. Em outras palavras, o baixo escore de ECG foi um dos critérios para instalação da monitoração da PIC em muitos dos pacientes deste estudo.

O tempo de internação pré-monitoração - variável que nos diz algo sobre a evolução do paciente, sobre o tempo transcorrido entre a indicação da monitoração da PIC e o seu início ou, ainda, sobre o tempo de exposição destes pacientes ao ambiente hospitalar - foi incluído neste estudo com o propósito de se obter mais informações que pudessem contribuir para a reflexão acerca de fatores de risco relacionados a complicações decorrentes da monitoração da PIC. Esta variável, no entanto, não foi objeto de investigação em estudos semelhantes a este.

Embora sem parâmetros de comparação para esta variável, o presente estudo evidencia o caráter agudo do quadro clínico dos pacientes aqui envolvidos, principalmente nos casos de TCE seguidos dos AVCs, nos quais não haja tempo para compensações da hipertensão intracraniana por meio dos mecanismos fisiológicos e em que ocorra e hemorragia ventricular $^{92}$.

O uso de antibioticoprofilaxia para ventriculite é discutido esporadicamente em alguns trabalhos. Wyler and Kelly ${ }^{65}$ encontraram em seus estudos uma taxa de $9 \%$ desta infecção nos pacientes que fizeram uso desta terapêutica profilática, contra $27 \%$ nos que não fizeram. Stenager et $\mathrm{al}^{64}$ constataram que somente um dos 10 pacientes que receberam antibiótico foi infectado, contra 14 dos 77 que não receberam. Embora a 
maioria dos estudos prévios aponte para a não redução da taxa de ventriculite entre os pacientes que fizeram uso de profilaxia e os que não fizeram, tais estudos foram realizados em populações pequenas, com o uso de antibióticos profiláticos seguindo tempos de introdução e duração da terapêutica desiguais na mesma amostra. A ausência de uniformidade nos métodos dessas pesquisas dificulta qualquer observação conclusiva e evidencia a necessidade de mais estudos controlados e randomizados, com amostras maiores para que se possa concluir algo mais consistente sobre a eficácia ou não dessa terapêutica.

No presente estudo, todos os pacientes receberam antibiótico profilático, sendo que a primeira dose foi administrada entre 2 horas antes da colocação do cateter e o momento de cateterização, tendo sido mantida até a retirada do mesmo. Desta forma, não foi possível comparar os situações de ausência de antibioticoprofilaxia. É importante lembrar que somente $46.8 \%$ dos pacientes receberam a profilaxia conforme protocolo definido pela Instituição com o uso de ceftriaxona. Os demais pacientes foram submetidos ao protocolo, no entanto, a ele foram associados diversos antibióticos como clindamicina, oxacilina e outros em menor freqüência, principalmente nos casos de TCE associado com politraumas. Ocorreram, ainda, casos em que houve eleição de um único antibiótico diferente da ceftriaxona.

Os resultados deste estudo mostraram a ausência de associação estatisticamente significativa entre o uso de antibiótico profilático e a ocorrência de ventriculite na população estudada. É preciso enfatizar, no entanto, que também neste estudo o resultado desta associação sofreu 
influência de uma padronização pouco rigorosa, devendo, portanto, ser relativizada. Novamente fica evidente a necessidade de mais pesquisas para sustentar segura e cientificamente o uso desse recurso, ao mesmo tempo beneficiando o paciente e evitando ao máximo o uso indiscriminado de antibióticos de amplo espectro, os quais, entre outros problemas, podem favorecer o aumento das infecções nosocomiais ${ }^{93}$.

A presença de cateteres, cirurgias, drenos e sondas de uma forma geral, por se tratarem de procedimentos invasivos, funcionam como "porta de entrada" para infecções ${ }^{94}$. Nos pacientes submetidos a monitoração da PIC elas podem facilitar a ocorrência de ventriculite.

A população deste estudo, por ser em sua maioria composta de pacientes com patologias graves ou moderadamente graves, todos possuíam algum outro tipo de cateter ou sonda além do utilizado para monitoração da PIC durante o período de seguimento da pesquisa. Em 91.1\% dos casos também houve a realização de cirurgias (neurológicas ou não) e em 34.2\% havia presença de algum tipo de dreno. Tal fato nos autoriza a inferir que este grupo de pacientes apresentava uma vulnerabilidade decorrente do quadro clínico complexo, potencializada pelo próprio processo terapêutico.

Considerando-se a relação do sexo dos pacientes com a presença de ventriculite, o que se obteve neste estudo foi que 100\% dos casos desta infecção ocorreram em homens. Este resultado difere de pesquisas divulgadas na literatura, as quais não apresentam relação entre essas duas variáveis $^{73}$. A divergência dos resultados pode ser decorrente do número limitado de mulheres na população do presente estudo (29,1\%). 
Um único caso de ventriculite ocorreu num paciente diagnosticado com AVC. Os outros vinte casos ocorreram em pacientes com TCE, não havendo caso algum entre os portadores de tumores. É possível que este fato tenha ocorrido em função da diferença numérica entre os diagnósticos dos pacientes deste estudo, isto é, número elevado de TCE e muito baixo de tumores e AVC.

Considerando-se apenas a população com TCE, pode-se observar associação estatisticamente significativa entre a hemorragia subdural e a presença de ventriculite. TCE aberto, fístulas LCR e hemorragia intraventricular, apontadas como fatores de risco por alguns autores ${ }^{14}$, não apresentaram associação significativa com ventriculite neste estudo, porém estamos cientes de que uma fístula LCR ou um TCE aberto são uma abertura das barreiras de proteção para a infecção, o que é facilmente explicado pela fisiopatologia no sistema nervoso central ${ }^{95}$.

Pesquisas têm mostrado que as hemorragias intraventriculares, assim como a presença de PIC acima de $20 \mathrm{mmHg}$ são fatores de risco para as ventriculites ${ }^{61}$, até porque muitas vezes demandam uma necessidade de prolongamento da permanência da monitoração da PIC. Neste estudo também não houve relação estatisticamente significativa entre ventriculite e hipertensão intracraniana acima de $20 \mathrm{mmHg}$, mais uma vez diferindo dos resultados encontrados na literatura.

Temas evidentes e recorrentes em várias pesquisas envolvendo monitoração da PIC são a duração da utilização deste procedimento nos pacientes e a ocorrência de ventriculite. Uns advogam a favor da retirada do cateter, principalmente no quinto dia da monitoração e recomendam a 
recateterização em outro lócus ventricular, nos casos em que sua manutenção for considerada necessária ${ }^{1,61}$. Para estes autores, o aumento da infecção se dá após o quinto dia e permanece crescendo com o tempo, numa relação quase linear e acumulativa. Outros defendem a não associação entre as variáveis e, portanto, não recomendam a troca de cateter intraventricular se não houver manifestação clínica que justifique esta conduta. Afirmam que as múltiplas ventriculostomias podem aumentar o risco de complicações, além de aumentar os custos hospitalares ${ }^{71,76}$.

No trabalho aqui elaborado, o tempo médio de permanência da monitoração da PIC foi de 6.7 dias, embora $54.5 \%$ dos cateteres foram retirados até o quinto dia como é recomendado por Mayhall et $\mathrm{al}^{61}$. As maiores permanências de monitoração foram em pacientes portadores de tumores e AVCs.

A freqüência de ventriculite encontrada neste estudo foi de $26.6 \%$. Este índice, embora esteja na faixa citada pela literatura consultada (0 a $45 \%)^{1,2,21,35,48,59-67,69,71-74,96}$, é elevado quando comparado aos índices da maioria dos estudos, os quais variam de 0 a $27 \%{ }^{14,21,59-71}$. Estas diferenças de resultados, entre outras coisas, podem estar relacionadas à falta de um consenso na definição de ventriculite, isto é, dependendo da abrangência que é dada a esta definição, os índices tendem a ser mais altos ou mais baixos.

No presente estudo, o diagnóstico de ventriculite foi realizado, em dois casos, nos três primeiros dias (sendo um com cultura positiva do LCR coletado no momento da punção do ventrículo), apresentando freqüência 
máxima entre o quarto e sexto dia (oito casos) e queda desta freqüência do sétimo ao décimo segundo dia (praticamente um caso por dia).

Cinco casos de ventriculite foram diagnosticados após a retirada do cateter, sendo que o último foi diagnosticado no décimo segundo dia após a sua retirada, isto é, ainda durante o período em que essa ocorrência se dá, segundo acreditamos, como conseqüência da cateterização ventricular prévia. Nesses casos de ventriculite pós-retirada de cateter, o período de permanência da monitoração variou de 3 a 6 dias.

Portanto, a freqüência de ventriculite neste estudo apresentou crescimento até o sexto dia e decréscimo irregular a partir desta data. Após o décimo segundo dia de monitoração da PIC com drenagem contínua do LCR, não houve ocorrência alguma de ventriculite até a retirada do último cateter no vigésimo quinto dia. No entanto, é necessário lembrar que poucos foram os pacientes mantidos com monitoração após este período (apenas oito), fato que provavelmente influiu no baixo percentual de ventriculite neste período.

Com isso, concluímos que a observação somente da freqüência diária de ventriculite na população dificulta uma análise mais consistente acerca da taxa diária desta infecção ao longo do tempo, fato observado em muitos estudos os quais só trazem esta freqüência. Essa taxa diária é calculada dividindo-se o número de infecções diagnosticadas no dia referido pelo número total de cateteres de pacientes sem ventriculite existentes no mesmo dia.

Através deste cálculo, nossas taxas diárias de ventriculite foram de $2.6 \%$ até três dias de monitoração, $6.4 \%$ de 4 a 5 dias, $11.4 \%, 4.2 \%, 5.3 \%$, 
$13.3 \%, 9.1 \%$ nos dias $6,7,8,9$ e 10 respectivamente, e ainda $11.1 \%$ no $12^{\circ}$ dia. Assim essa taxa apresentou alguns picos, não sendo acumulativa e linear, tornando-se nula após o décimo segundo dia e apresentando um menor índice nos três primeiros dias, seguidos dos cinco primeiros. Resultado semelhante aos de outros autores ${ }^{73}, 96$, os quais baseiam-se nestes achados ao recomendar a retirada do cateter o mais breve possível .

Não houve associação estatisticamente significante entre o tempo de permanência da monitoração e a presença de ventriculite, no entanto é preciso lembrar que a quantidade de pacientes infectados (21) pode ter dificultado a evidência desta associação. De qualquer modo, a distribuição temporal do surgimento destes 21 casos de ventriculite sugere que o tempo de permanência do cateter é um fator importante a ser considerado no acompanhamento destes pacientes.

A análise da ocorrência de ventriculite em pacientes submetidos a mais de uma ventriculostomia não foi possível neste estudo, uma vez que esta situação foi observada em apenas quatro casos. Nenhum deles evoluiu com ventriculite.

Intercorrências no momento da cateterização ou durante manipulações do sistema não apresentaram associação estatisticamente significativa com a ocorrência de ventriculite no presente estudo, fato que também pode ter sido eclipsado pelo número restrito de pacientes infectados. Estas intercorrências, em sua maioria, decorreram de desconexões do sistema que afetam diretamente o ambiente asséptico requerido pela terapêutica em estudo. 
O fato de quase todos os sujeitos desta pesquisa terem sido submetidos a algum tipo de neurocirurgia durante o período de seguimento impossibilitou a comparação entre os pacientes cirurgiados e os não cirurgiados que visasse analisar o comportamento desta variável em relação à presença de ventriculite. O interesse em analisar a relação destas variáveis sustentava-se no fato de tal relação ter sido apontada em publicações consultadas $^{67,71}$.

Em relação ao agente infectante das ventriculites, Park et al $^{96} \mathrm{e}$ Mayhall et $\mathrm{al}^{61}$ encontraram o Staphylococcus coagulase negativo na maioria das culturas de seus estudos seguido do Enterobacter aerogenes em outros casos esporádicos.

Em $81 \%$ dos casos de ventriculite da população deste estudo, as bactérias foram isoladas em séries, em meio de cultura, tendo sido o Acinetobacter baumannii, seguido do Staphylococcus coagulase negativo, os agentes infectantes mais freqüentes. Dos pacientes diagnosticados por meio de cultura positiva, $70.6 \%$ apresentaram também febre e outras alterações citológicas e bioquímicas sugestivas de ventriculite, na ausência de outro foco infeccioso conhecido.

Somente em $19 \%$ dos casos de ventriculite o diagnóstico foi feito por meio da presença de febre associada a alterações bioquímicas e citológicas do LCR compatíveis com ventriculite, porém com ausência de cultura positiva do LCR e de outro foco infeccioso conhecido. Embora numericamente reduzidos, os dados aqui obtidos são compatíveis com os de outros autores que afirmam que estas alterações no LCR podem ter grande valor diagnóstico ${ }^{61,83}$. 
No presente estudo, foram consideradas como ventriculite ambas as situações apresentadas, uma vez que a literatura tem questionado o diagnóstico feito com base apenas na cultura de LCR. Os estudos que trazem este questionamento o justificam afirmando que é possível a ocorrência de resultados falsos negativos em função da pequena carga de agentes infecciosos, ou ainda por ser difícil a detecção de infecções transitórias quando a coleta liquórica não apresenta uma freqüência regular $^{15,96}$.

$66.7 \%$ dos pacientes deste estudo receberam associação de antibióticos para tratamento da ventriculite. A vancomicina e a ceftazidima foram as mais utilizadas. O tempo de antibioticoterapia foi variável, em torno de uma média de 17.4 dias. Esta informação destaca as repercussões negativas advindas da ventriculite, pois, além de contribuir para o aumento tempo de internação do paciente e do custo do tratamento, amplia a vulnerabilidade do paciente, em virtude de, entre outras razões, do aumento da nefrotoxicidade e outras iatrogênias causadas ou potencializadas pelo uso de antibióticos ${ }^{97}$. Apesar da importância deste assunto, ele é pouco abordado nos estudos consultados.

O percentual de pacientes, neste estudo, que desenvolveram infecções em outros sítios que não o ventrículo, foi de $12.7 \%$ da população, sendo que $90 \%$ destes desenvolveram ventriculite além desta infecção. Por outro lado, dos pacientes com ventriculite, $42.9 \%$ tinham infecções em outros focos. A relação da ocorrência de infecção nos ventrículos e em outros sítios foi estatisticamente significativa neste estudo. 
Rebuck et $\mathrm{a}^{53}$, com base em seus estudos, reconhecem que esta relação realmente existe, porém, afirmam que, na maioria das vezes o agente causador isolado em culturas de outros sítios diferem dos isolados nas culturas de LCR. Nesta pesquisa, esta diferença ocorreu em $66,7 \%$ dos pacientes que desenvolveram os dois tipos de infecção.

Rebuck et $\mathrm{al}^{53}$ observaram, ainda, que as infecções mais freqüentemente associadas à ventriculite foram as pneumonias e as de trato urinário. Os resultados do presente estudo diferiram dos encontrados por estes autores, uma vez que, aqui $60 \%$ dos pacientes com ventriculites possuíam as septicemias associadas, dados que se assemelharam aos encontrados nos estudos de Holloway et al ${ }^{73}$ e Clark et al ${ }^{98}$.

O início das infecções que ocorreram na vigência da monitoração da PIC deu-se, em média, no quinto dia após a colocação do cateter, nos casos de infecções em outros sítios que não o ventrículo e, em média, no sexto dia nos casos de ventriculite.

As ventriculites desenvolvidas após a retirada do cateter ocorreram, em média, no sétimo dia, enquanto que as infecções em outros surgiram, em média, no quarto dia. Em ambas as situações, as infecções em outros sítios se desenvolveram precocemente em relação às ventriculites. Estes resultados permitem a inferência de que as infecções não ventriculares parecem ser fatores de risco para ventriculite e não o contrário.

Em relação ao destino dos pacientes submetidos à monitoração da PIC, foi observado neste estudo que $38.0 \%$ permaneceram internados na UTI e 17.7\% evoluíram para óbito após duas semanas da retirada do cateter (nos casos dos pacientes sem ventriculite) ou, ao final do tratamento, para 
ventriculite (nos casos em que esta ocorreu). Não houve relação estatisticamente significativa entre o destino destes pacientes e a presença de ventriculite. Aparentemente este destino está relacionado à gravidade do quadro clínico neurológico inicial destes pacientes. O escorre da ECG obtido no momento final do seguimento da pesquisa foi em média 11.5 pontos. É importante informar que a média dos escores da ECG foi quase idêntica ao se comparar os pacientes com e sem ventriculite. 
Conclusão 


\section{6- CONCLUSÃo}

A população deste estudo foi de 79 pacientes, dos quais $70.9 \%$ eram do sexo masculino, com média de 33.7 anos, sendo que os diagnósticos presentes em $82.3 \%$ eram referentes ao TCE seguido de tumores e AVCs, apresentando uma freqüência mais expressiva as hemorragias subdural e subaraquinóidea, swelling, contusão, lesão axonal difusa e hemorragia extradural.

A média do escore da ECG no momento da internação nesta população foi de 8 pontos, atingindo 11.5 pontos no final do seguimento efetuado pela pesquisadora. O tempo de internação pré-monitoração médio foi de 1.6 dias, mostrando o caráter agudo do processo patológico da maioria dos pacientes incluídos, os quais tiveram indicação de rápido monitoramento e drenagem do LCR, pelas possíveis alterações nos mecanismos reguladores da PIC.

Todos os pacientes receberam antibioticoprofilaxia, porém somente 46.8\% com ceftriaxona, conforme protocolo definido pela Instituição. Esta terapia não apresentou associação estatisticamente significativa com a diminuição da taxa de ventriculite.

A taxa de ventriculite foi de $26.6 \%$, com uma média de permanência do cateter de 6.7 dias e taxas diárias desta infecção variáveis. Não encontramos associação estatisticamente significativa entre tempo de monitoramento e infecção, porém houve um aumento do índice diário de ventriculite após os três primeiros dias e picos no $6^{\circ}, 9^{\circ}$ e $12^{\circ}$ dia, indicando 
uma provável ligação não acumulativa ou linear, que necessita de mais estudos em séries maiores.

Os diagnósticos de ventriculite foram realizados, quase em sua totalidade, por meio de cultura positiva do LCR, sendo que na maioria destes casos também havia alterações bioquímicas e citológicas no líquor compatíveis com ventriculite, além de febre e ausência de outro foco infeccioso conhecido.

Outras variáveis avaliadas neste estudo, que apresentaram associação direta com a ocorrência de ventriculite, foram o sexo masculino, hemorragia subdural - sendo este o único diagnóstico que apresentou significância estatística - e infecções em outros sítios diferentes do ventrículo, principalmente a sepses.

Variáveis como idade, procedimentos invasivos, TCE aberto, fístulas LCR, hemorragia intraventricular, múltiplas ventriculostomias, presença de PIC acima de $20 \mathrm{mmHg}$, intercorrências durante a cateterização ou manutenção do cateter, não apresentaram associação estatisticamente significativa com a taxa de ventriculite, no entanto muitas destas variáveis estiveram presentes em poucos casos dificultando uma conclusão definitiva. 
Anexos 


\section{Anexo I}

\section{HOSPITAL DAS CLÍNICAS}

DA FACULDADE DE MEDICINA DA UNIVERSIDADE DE SÃo PAULO

CAIXA POSTAL, 8091 - SÃO PAULO - BRASIL

DIRETORIA CLÍNICA

\section{Comissão de Ética para Análise de Projetos de Pesquisa}

\section{APROVAÇÃO}

A Comissão de Ética para Análise de Projetos de Pesquisa - CAPPesq da Diretoria Clínica do Hospital das Clínicas e da Faculdade de Medicina da Universidade de São Paulo, em sessão de 08.10.03, APROVOU o Protocolo de Pesquisa $n^{\circ}$ 741/03, intitulado: "Infecção pelo manuseio da monitorização intraventricular da pressão intracraniana" apresentado pelo Departamento de NEUROLOGIA, inclusive o Termo de Consentimento Livre e Esclarecido.

Pesquisador(a) Responsável: DR. ALMIR FERREIRA DE ANDRADE

Pesquisador(a) Executante: SRA. SILVIA ROCHA CANGUSSÚ

CAPPesq, 08 de Outubro de 2003.

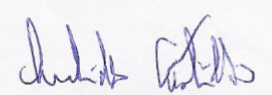

PROF. DR. EUCLIDES AYRES DE CASTILHO Presidente da Comissão de Ética para Análise de Projetos de Pesquisa

OBSERVAÇÃO: Cabe ao pesquisador elaborar e apresentar à CAPPesq, os relatórios parciais e final sobre a pesquisa (Resolução do Conselho Nacional de Saúde $n^{\circ} 196$, de 10.10.1996, inciso IX.2, letra "c") 


\section{Anexo II \\ HOSPITAL DAS CLÍNICAS \\ DA}

FACULDADE DE MEDICINA DA UNIVERSIDADE DE SÃO PAULO

TERMO DE CONSENTIMENTO LIVRE E ESCLARECIDO

(Instruções para preenchimento no verso)

\section{I - DADOS DE IDENTIFICAÇÃO DO SUJEITO DA PESQUISA OU RESPONSÁVEL LEGAL}

\section{NOME DO PACIENTE}

DOCUMENTO DE IDENTIDADE № : SEXO : .M $\square \quad F$

DATA NASCIMENTO:

ENDEREÇO

№

APTO:

BAIRRO:

CEP:

TELEFONE: DDD

2.RESPONSÁVEL LEGAL

NATUREZA (grau de parentesco, tutor, curador etc.)

DOCUMENTO DE IDENTIDADE :

SEXO: $M \square \quad F$

DATA NASCIMENTO.:

ENDEREÇO:

№

APTO:

BAIRRO

CIDADE:

CEP

TELEFONE: DDD

)

\section{II - DADOS SOBRE A PESQUISA CIENTÍFICA}

1. TÍTULO DO PROTOCOLO DE PESQUISA : INFECÇÃO NA MONITORAÇÃO

INTRAVENTRICULAR DA PRESSÃO INTRACRANIANA COM DRENAGEM CONTÍNUA DO LÍQUIDO CEFALORRAQUIANO

2. PESQUISADOR: Silvia Rocha Cangussú

CARGO/FUNÇÃO: Mestranda de enfermagem

INSCRIÇÃO CONSELHO REGIONAL № 0104451

UNIDADE DO HCFMUSP: Instituto Central

3. AVALIAÇÃO DO RISCO DA PESQUISA:

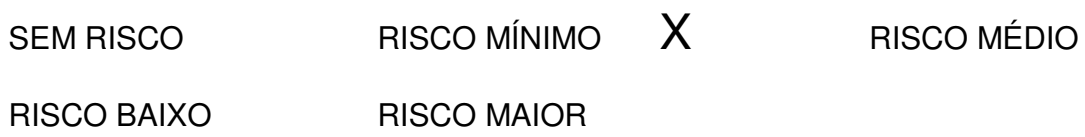

(probabilidade de que o indivíduo sofra algum dano como consequência imediata ou tardia do estudo) 4.DURAÇÃO DA PESQUISA : dois anos e seis meses 
III - REGISTRO DAS EXPLICAÇÕES DO PESQUISADOR AO PACIENTE OU SEU REPRESENTANTE LEGAL SOBRE A PESQUISA CONSIGNANDO:

1. A pesquisa tem como objetivo verificar a freqüência de infecções decorrentes do método de monitoração intermitente da pressão intracraniana (PIC) com drenagem contínua do líquido cefalorraquiano (LCR) e avaliar os possíveis fatores de risco para esta complicação. Com isto, visamos prevenir ou minimizar a ocorrência destes fatores de risco, tornando o método de monitoração mais seguro.

O paciente será acompanhado durante todo o período em que permanecer com o monitor de PIC através de informações de seu prontuário e do arquivo de seus exames laboratoriais, para avaliar sua evolução durante o período. Todas essas informações colhidas serão confidenciais, garantindo-se o sigilo e a privacidade do paciente.

Nesta pesquisa os riscos e desconfortos para o paciente serão mínimos, pois não haverá modificação em seu tratamento. Não haverá benefício ao paciente incluído no estudo, ele só estará contribuindo para uma melhor avaliação da ocorrência de infecção proporcionada pelo método de monitorização de PIC, assim como, do maior conhecimento dos fatores de risco para esta complicação,e assim para a prevenção destes.

\section{IV - ESCLARECIMENTOS DADOS PELO PESQUISADOR SOBRE GARANTIAS DO SUJEITO DA PESQUISA CONSIGNANDO:}

1. O paciente ou seu responsável legal poderão ter acesso a qualquer tempo, às informações relacionadas à pesquisa, inclusive para esclarecer eventuais dúvidas.

2. O paciente e/ou seu responsável legal poderá retirar seu consentimento a qualquer momento e deixar de participar do estudo, sem que isso traga prejuízo à continuidade da assistência.

3. Todas as informações colhidas serão confidenciais, garantindo-se o sigilo e a privacidade do paciente. 


\section{V - CONSENTIMENTO PÓS-ESCLARECIDO}

Declaro que, após convenientemente esclarecido pelo pesquisador e ter entendido o que me foi explicado, consinto em participar do presente Protocolo de Pesquisa

São Paulo, de de 200

$\overline{\text { assinatura do sujeito da pesquisa ou responsável legal }}$ 


\section{FICHA DE COLETA DE DADOS}

Paciente número:

Número de registro:

\section{Dados Gerais}

1) Identificação do paciente

1.1- Idade:

1.2- Sexo:

2) Diagnóstico principal:

3) Outros procedimentos invasivos:

3.1-Cateterização:

Tipo:

3.2-Sondagem:

Tipo:

3.3-Cirurgia:

Tipo:

3.4-Drenagem: Tipo:

3.5-Outros: Tipo:

4) Tempo de internação no Hospital:

5) Destino após duas semanas de retirada do cateter:

5.1- Alta: _ 5.2-Continuação da internação na UTI:

5.3- Óbito:

6) Escala de Glasgow:

6.1- Na chegada ao hospital:

6.2- Na internação na UTI:

6.3- Após a $2^{\mathrm{a}}$ semana:

\section{Dados Relacionados à Monitoração da PIC}

1)Tempo de monitoração da PIC:

2) Antibiótico profilático:

2.1- Sim:

2.2- Não:

Qual:

Início:

Término:

Posologia: 
3) Presença de ventriculite:

3.1- Sim:

3.2- Não:

Dia da monitoração o qual houve infecção:

Agente causal:

Qual antibiótico para tratamento:

Início:

Término:

Posologia:

\section{Fatores de Risco}

1) Procedimentos neurocirúrgicos prévios:

1.1- Sim:

1.2- Não:

Qual:

2) Ventriculostomias prévias:

2.1- Sim:

2.2- Não:

Quantas:

3) Intercorrências no momento da cateterização do ventrículo:

3.1- Sim:

3.2- Não:

Qual:

4) Presença de fístula liquórica:

4.1- Sim:

4.2- Não:

5) Presença de TCE aberto:

5.1- Sim:

5.2- Não:

Causa do TEC aberto:

6) Presença de hemorragia intraventricular prévia:

6.1- Sim:

6.2- Não:

7) PIC acima de $20 \mathrm{mmHg}$ :

7.1- Sim:

7.2- Não:

Dia de monitoração:

8) Presença de infecções em locais diferentes do SNC:

8.1- Sim:

8.2- Não:

Local:

Agente: 
Dia que foi diagnosticada:

Qual o antibiótico:

9) Presença de febre:

\begin{tabular}{|l|l|l|l|l|l|l|}
\hline Data & & & & & & \\
\hline Temperatura & & & & & & \\
\hline
\end{tabular}

IV- Dados Relacionados ao Perfil do LCR

A)

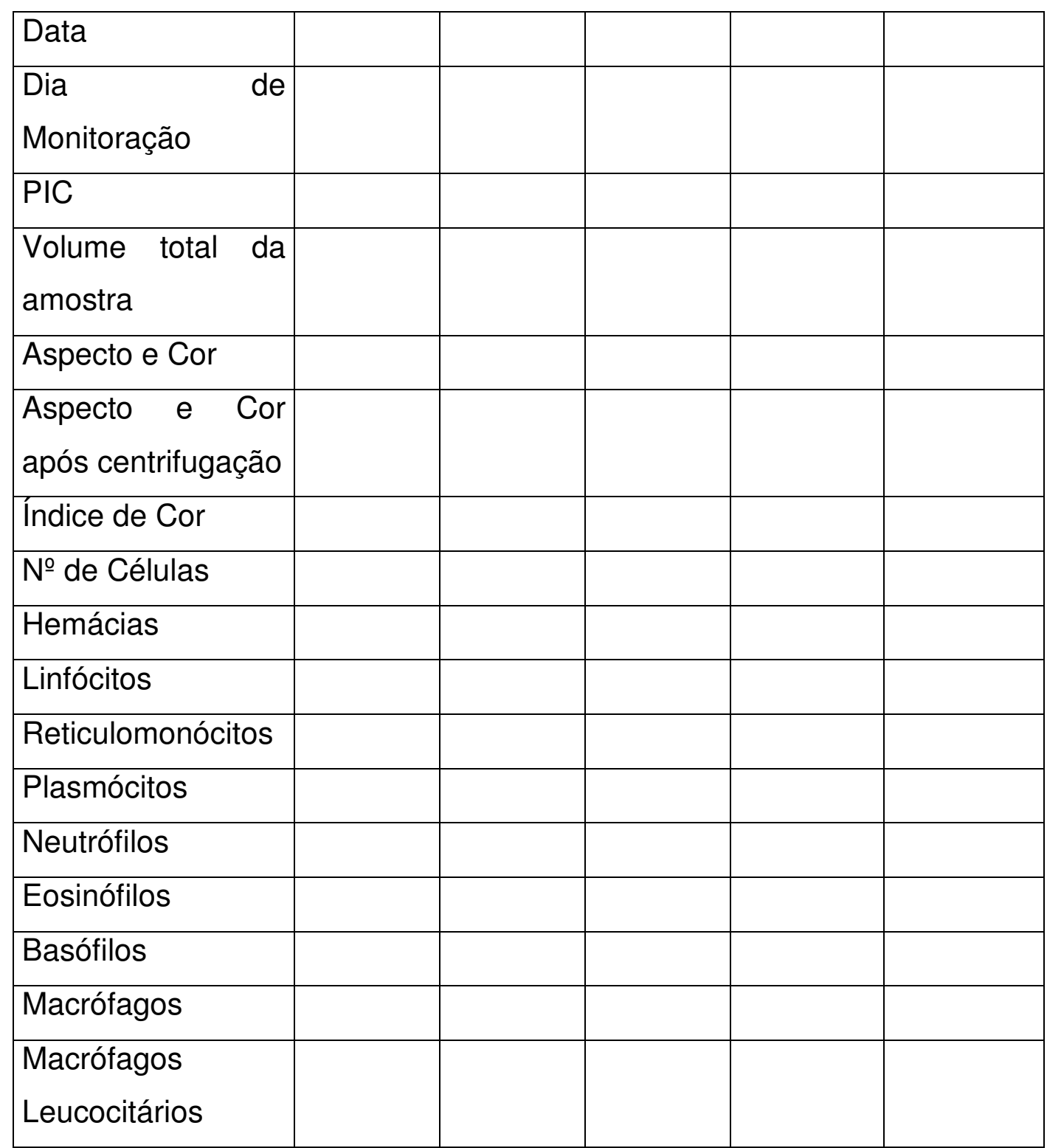




\begin{tabular}{|l|l|l|l|l|l|}
\hline Macrófagos & & & & & \\
Hemáticos & & & & & \\
\hline Pigmentadosasos & & & & & \\
\hline Uréia & & & & & \\
\hline Proteína Total & & & & & \\
\hline Glicose & & & & & \\
\hline Cloretos & & & & & \\
\hline Citologia Oncótica & & & & & \\
\hline Reação de Pandy & & & & & \\
\hline Lactato & & & & & \\
\hline Bacterioscopia & & & & & \\
\hline Cultura Geral & & & & & \\
\hline Outros & & & & & \\
\hline
\end{tabular}

B) Outras culturas:

1) Sangue:

1.1-Positiva:__ 1.2- Negativa:____ Patógeno:

2) Urina:

2.1- Positiva:

Negativa:

Patógeno:

3) Outras: Origem:

3.1- Positiva: 3.2- Negativa:

Patógeno: 
Anexo IV

FICHA DE MANIPULACÕES E INTERCORRÊNCIAS COM O SISTEMA DE MONITORACÃO

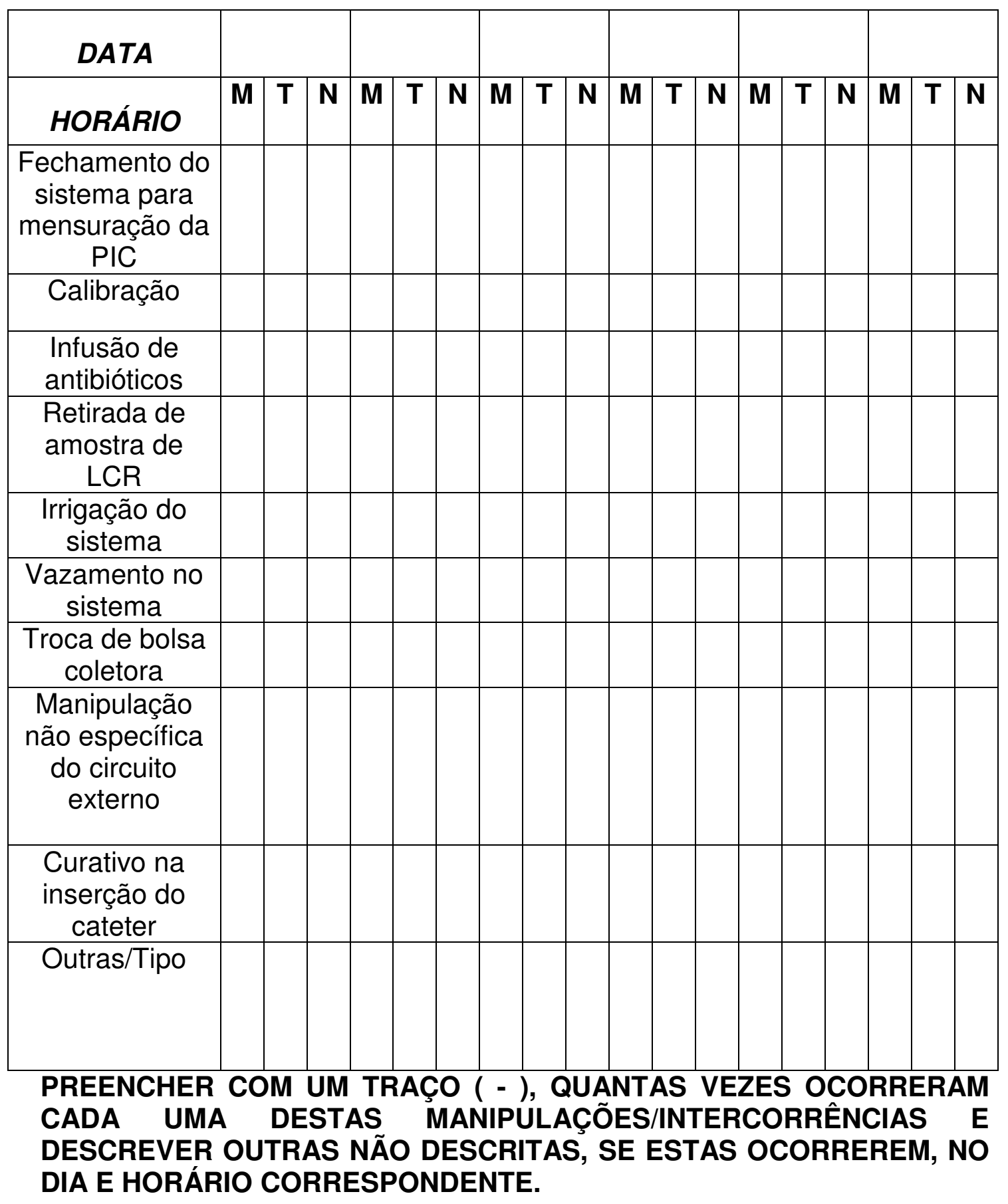


Referências Bibliográficas 
1. Narayan RK, Kishore PRS, Becker DP, Ward JD, Enas GG, Greenberg RP, et al. Intracranial pressure: to monitor or not to monitor? A review of our experience with severe head injury. J Neurosurg 1982; 56:650-659.

2. Venes J. Intracranial pressure monitoring in perspective. Child's Brain 1980; 7:236-251.

3. Becker DP, Miller JD, Ward JD, et al. The outcome from severe head injury with early diagnosis and intensive management. J Neurosurg 1977; 47:491-502.

4. Bowers SA, Marshall LF. Outcome in 200 consecutive cases of severe head injury in San Diego County: a prospective analysis. Neurosurgery 1980; 6:237-242.

5. Byrnes DP, Ducker TB. Continuous measurement of intracranial pressure in 127 severe head injuries. In: Shulman K, Marmarou A, Miller JD, et al. Intracranial Pressure IV. Berlin/Heidelberg/New York: Springer-Verlag; 1980. p.73-75.

6. Lobato RD, Rivas JJ, Portillo JM, et al. Prognostic value of the intracranial pressure levels during the acute phase of severe head injuries. Acta Neurochir Suppl 28 1979; 70-73.

7. Lundberg $\mathrm{N}$, Troupp $\mathrm{H}$, Lorin $\mathrm{H}$. Continuous recording of the ventricular-fluid pressure in patients with severe acute traumatic brain injury. A preliminary report. J Neurosurg 1965; 22:581-590.

8. Marshall LF, Smith RW, Shapiro HM. The outcome with agressive treatment in severe head injuries. Part 1: The significance of intracranial pressure monitoring. J Neurosurg 1979; 50:20-25.

9. Miller JD, Becker DP, Ward JD, et al: Significance of intracranial hypertension in severe head injury. J Neurosurg 1977; 47:503-516.

10. Miller JD, Sweet RC, Narayan RK, et al. Early insults to the injured brain. JAMA 1978; 240:439-442.

11. Tsementzis SA, Gordon A, Gillingham FJ. Prognostic signs during continuous monitoring of the ventricular fluid pressure in patients with severe brain injury. Acta Neurochir Suppl 28 1979; 78-84. 
12. Winn HR, Dacey RG, Jane JA. Intracranial subarachnoid pressure recording: experience with 650 patients. Surg Neurol 1977; 8:41-47.

13. Andrade AF. Medida continua da pressão intracraniana no traumatismo cranioencefálico. [dissertação] São Paulo (SP): Faculdade de Medicina da USP; 1982.

14. Bader MK, Littlejohns L, Palmer S. Ventriculostomy and intracranial pressure monitoring: in search of a $0 \%$ infection rate. Heart Lung 1995; 24(2):166-72.

15. Spina-França A. Líquido cefalorraqueano. In: Tolosa APM, Canelas HM(eds). Propedêutica neurológica - temas essenciais. $2^{a}$ ed. São Paulo: Editora Sarvier 1971; 443-465 cap26.

16. American College of Surgeons. Advanced Trauma Life Support for Doutors ATLS. Head injury. Trauma craniencefálico. $6^{\text {th }}$ ed. Chicago; 1997. p.181-206.

17. Ghajar J. Intracranial pressure monitoring techniques. New Horiz 1995;3(3):395-9.

18. Guillaume J, Janny P. Manometrie intracranienne continue. Rev Neurol (Paris) 1951; 84:131-142.

19. Guyot LL, Dowling C, Diaz FG, Michael DB. Cerebral monitoring devices: analysis of complications. Acta Neurochir Suppl (Wien) 1998; 71:47-9.

20. Hickman KM, Mayer BL, Muwaswes M. Intracranial pressure monitoring: review of risk factors associated with infection. Heart Lung 1990; 19(1):84-90.

21. Smith RW, Alksne JF. Infections complicating the use of external ventriculostomy. J Neurosurg 1976; 44:567-70.

22. Miller JD, Piper IR, Statham PFX. ICP monitoring: indications and techniques. In: Scheld WM, Whitley RJ, Durack DT. Infections of the Central Nervous System. Philadelphia: Lippincott-Raven Publishers; 1997. cap.31,p.429-444.

23. Lundberg N. Continuous recording and control of ventricular fluid pressure in neurosurgical practice. Acta Psychiatr Scand 36(suppl 49) 1960; 1-193. 
24. Adson AW, Lillie WL. The relationship of intracranial pressure, choked discs and intraocular pressure. Trans Am Acad Ophthalmol 1927; 30:138-54.

25. Anton N. Pressure curves from cerebrospinal fluid. Acta Med Scand 1946; 170:439-62.

26. Ropper $\mathrm{AH}$. In favor of intracranial pressure monitoring and aggressive therapy in neurologic practice. Arch Neurol 1985; 42:11946.

27. Saul TG, Ducker TB. Effect of intracranial pressure monitoring and aggressive treatment on mortality in severe head injury. J Neurosurg 1982; 56:498-503.

28. Chambers IR, Kane PJ, Choksey MS, et al. An evaluation of the Camino ventricular bolt system in clinical practice. Neurosurgery 1993; 33:866-868.

29. Allen R. Intracranial pressure: a review of clinical problems, measurement techniques and monitoring methods. J Med Eng Technol 1986; 10:299-320.

30. Vries JK, Becker DP, Young HF. A subarachnoid screw for monitoring intracranial pressure. Technical note. J Neurosurg 1973; 39:416-419.

31. Andrade AF, Teixeira MJ, Bacheschi LA, Manreza LA, Vellutini EAS, Ribas GC, Almeida GM. Medida contínua da pressão intracraniana com parafusos: modificação técnica. Arq Bras Neurocirurg 1983; 2:143-148.

32. Andrade AF. Medida continua da pressão intracraniana para avaliação do traumatismo cranioencefálico. [tese] São Paulo (SP): Faculdade de Medicina da USP; 1990.

33. Wilkinson HA. The intracranial pressure-monitoring cup catheter. Technical note. Neurosurgery 1977; 1:139-141.

34. Wald A, Post $K$, Ransohoff J, et al. A new technique for monitoring epidural ICP. Med Instrum 1977; 11:352-354.

35. Friedman WA, Vries JK. Percutaneous tunnel ventriculostomy. Summary of 100 procedures. J Neurosurg 1980; 53:662-665. 
36. McGraw CP. Continuous intracranial pressure monitoring: review of techniques and presentation of method. Surg Neurol 1976; 6:149-155.

37. Miller JD. Intracranial pressure monitoring. Br J Hosp Med 1978; 19:497-503.

38. Piek J, Bock WJ. Continuous monitoring of cerebral tissue pressure in neurosurgical practice. Intensive Care Med 1990; 16:184-188.

39. Piek J, Kosub B, Kuch F, et al. A practical technique for continuous monitoring of cerebral tissue pressure in neurosurgical patients. Preliminary results. Acta Neuroch (Wien) 1987; 87:144-149.

40. Gopinath SP, Robertson CS, Constant CF, et al. Clinical evaluation of a miniature strain-gauge transducer for monitoring intracranial pressure. Neurosurgery 1995; 36:1137-1141.

41. Chambers IR, Mendelow AD, Sinar EJ, et al. A clinical evaluation of the Camino subdural screw and ventricular monitoring kits. Neurosurgery 1990; 26:421-423.

42. Gambardella G, d'Avella D, Tomasello F. Monitoring of brain tissue pressure with a fiberoptic device. Neurosurgery 1992; 31:918-921.

43. Gambardella G, Zaccone D, Cardia E, et al. Intracranial pressure monitoring children: Comparison of external ventricular device with fiberoptic system. Childs Nerv Syst 1993; 9:470-473.

44. Barlow $P$, Mendelow $A D$, Lawrence $A E$, et al. Clinical evaluation of two methods of subdural pressure monitoring. J Neurosurg 1985; 63:578-582.

45. Czech T, Korn A, Reinprecht A, et al. Clinical evaluation of a new epidural pressure monitor. Acta Neurochir (Wien) 1993; 125:169-172.

46. Kosteljanetz M, Borgesen SE, Stjernholm P, et al. Clinical evaluation of a simple epidural pressure sensor. Acta Neurochir (Wien) 1986; 83:108-111.

47. Mendelow AD, Rowan JO, Murray L, et al. A clinical comparison of subdural screw pressure measurements with ventricular pressure. $J$ Neurosurg 1983; 58:45-50. 
48. Mollman HD, Rockswold GL, Ford SE. A clinical comparison of subarachnoid catheters to ventriculostomy and subarachnoid bolts: A prospective study. J Neurosurg 1988; 68:737-41.

49. Powell M, Crockard HA. Behavior of an extradural pressure monitor in clinical use. J Neurosurg 1985; 6375-749.

50. Schickner DJ, Young RF. Intracranial pressure monitoring: Fiberoptic monitor compared with the ventricular catheter. Surg Neurol 1992; 7:251-254.

51. Weaver DD, Winn HR, Ane JA. Differential intracranial pressure in patients with unilateral mass lesions. J Neurosurg 1982; 56:660-665.

52. Yablon JS, Lantner HJ, McCormack TM, et al. Clinical experience with a fiberoptic intracranial pressure monitor. J Clin Monit 1993; 9:171-175.

53. Rebuck JA, Murry KR, Rhoney DH, Michael DB, Coplin WM. Infection related to intracranial pressure monitors in adults: analysis of risk factors and antibiotic prophylaxis. J Neurol Neurosurg Psychiatry 2000; 69(3):381-4.

54. Khan SH, Kureshi IU, Mulgrew T, Ho SY, Onyiuke HC. Comparison of percutaneous ventriculostomies and intraparenchymal monitor: a retrospective evaluation of 156 patients. Acta Neurochir Suppl (Wien) 1998; 71:50-2.

55. Bering EA Jr. A simplified apparatus for constant ventricular drainage. J Neurosurg 1951; 8:450-2.

56. Kusske JA, Turner PT, Ojemann GA, Harris AB. Ventriculostomy for the treatment of acute hydrocephalus following subarachnoid hemorrhage. J Neurosurg 1973; 38:591-5.

57. Grant FC. The value of hypertonic solutions by mouth, by rectum, or by intravenous injection for the reduction of increased intracranial pressure. Res Publ Assoc Res Nerv Ment Dis 1929; 8:437-54.

58. Poppen JL. Ventricular drainage as a valuable procedure in neurosurgery: report of a satisfactory method. Arch Neurol Psychiatry 1943; 50:587-9. 
59. Aucoin PJ, Kotilainen HR, Gantz NM, Davidson R, Kellog P, Stone B. Intracranial pressure monitors: epidemiologic study of risk factors and infections. Am J Med 1986; 80:369-76.

60. Bogdahn V, Lau W, Hassel W, Gunreben G, Mertens HG, Brawanski A. Continous pressure controlled external ventriculostomy drainage for treatment of acute hydrocephalus: evaluation of risk factors. Neurosurgery 1992; 31:898-904.

61. Mayhall CG, Archer NH, Lamb VA, Spadora AC, Baggett JW, Ward JD, Narayan RK. Ventriculostomy-related infections. A prospective epidemiologic study. N Engl J Med 1984; 310(9):553-9.

62. Franges EZ, Beideman ME. Infections related to intracranial pressure monitoring. J Neurosci Nurs 1988; 20:94-103.

63. Kanter RK, Weiner LB, Patt AM, Robson L. Infectious complications and duration of ICP monitoring. Crit Care Med 1985; 13:837-9.

64. Stenager E, Gerner-Schmidt P, Kock-Jensen C. Ventriculostomyrelated infection: an epidemiological study. Acta Neurochir (Wien) 1986; 83:20-3.

65. Wyler AR, Kelly WA. Use of antibiotics with external ventriculostomies. J Neurosurg 1972; 37:185-7.

66. Rosner M, Becker DP. ICP monitoring: Complications and associated factors. Clin Neurosurg 1976; 23:494-519.

67. Schultz M, Moore K, Foote AW. Bacterial ventriculitis and duration of ventriculostomy catheter insertion. J Neurosci Nurs 1993; 25:158-64.

68. Chan KH, Mann KS. Prolonged therapeutic external ventricular drainage: a prospective study. Neurosurgery 1988; 23:436-8.

69. Clark WC, Muhlbauer MS, Lowrey R, et al. Complications of intracranial pressure monitoring in trauma patients. Neurosurgery 1989; 25:20-4.

70. Holloway KL, Barnes T, Choi S, et al. Ventriculostomy infections: the effect of monitoring duration and catheter exchange in 584 patients. $J$ Neurosurg 1996; 85:419-24. 
71. Winfield JA, Rosenthal P, Kanter RK, Casella G. Duration of intracranial pressure monitoring does not predict daily risk of infectious complications. Neurosurgery 1993. 33(3):424-30.

72. Jones $\mathrm{CC}$, Cayard $\mathrm{CH}$. Care of ICP monitoring devices: a nursing responsibility. J Neurosurg Nurs 1982; 14(5):255-61.

73. Holloway KL, Barnes T, Choi S, Bullock R, Marshall LF, Eisenberg HM, Jane JA Ward JD, Young HF, Marmarou A. Ventriculostomy infections: the effect of monitoring duration and catheter exchange in 584 patients. J Neurosurg 1996 sept; 85:419-424.

74. Lyke KE, Obasanjo OO, Williams MA, O’Brien M, Chotani R, Perl TM. Ventriculitis complicating use of intraventricular catheters in adult neurosurgical patients. Clin Infect Dis 2001; 33:2028-2033.

75. Sundbärg G, Kjällquistt A, Lundberg N, Pontén U. Complications due to prolonged ventricular fluid pressure recordings in clinical practice. In: Brock $\mathrm{M}$, Dietz $\mathrm{H}$, eds. Intracranial pressure: experimental and clinical aspects. Berlin: Springer-Verlag, 1972:348-52.

76. Kanter RK, Weiner LB. Ventriculostomy-related Infections. N Engl J Med 1984; 311(15):987.

77. Ohrstrom JK, Skou JK, Ejlertsen T, Kosteljanetz M. Infected ventriculostomy: Bacteriology and treatment. Acta Neurochir (Wien) 1989; 100:67-69.

78. Kaye W. Catheter and infusion-related sepsis: the nature of the problem and its prevention. Heart Lung 1982; 11:221-8.

79. Stone HH, Haney BB, Kolb BS, Geheber CE, Hooper CA. Prophylactic and preventive antibiotic therapy. Ann Surg 1979; 189:691-9.

80. Haines SJ. Systemic antibiotic prophylaxis in neurological surgery. Neurosurgery 1980; 6:355-61.

81. Nikas DL, Konkoly R. Nursing responsibilities in arterial and intracranial pressure monitoring. J Neurosurg Nurs 1975; 7:116-22.

82. Robinet K. Increased intracranial pressure: management with an intraventricular catheter. J Neurosurg Nurs 1985; 17:95-104. 
83. Garner JS, Jarvis WR, Emori TG, et al. CDC definitions for nosocomial infections. Am J Infect Control 1988; 16:128-40.

84. Rosner B. Fundamentals of Biostatistics. $2^{\text {nd }}$ ed. Boston: PWS Publishers; 1986.

85. Dantas Filho VP, Falcão ALE, Sardinha LAC, Facure JJ, Araújo S, Terzi RGG. Fatores que influenciaram a evolução de 206 pacientes com trauma craniencefálico grave. Arq Neuropsiquiatr 2004 Jun; $62(2 A): 313-8$.

86. Tiret L, Hausherr E, Thicoipe M, Garros B, Maurette P, Castel JP, Hatton $F$. The epidemiology of head trauma in Aquitaine (France), 1986: a community-based study of hospital admissions and deaths. Int J Epidemiol. 1990 Mar;19(1):133-40.

87. Masson F, Thicoipe M, Aye P, Mokni T, Senjean P, Schmitt V, Dessalles PH, Cazaugade M, Labadens P; Aquitaine Group for Severe Brain Injuries Study. Epidemiology of severe brain injuries: a prospective population-based study. J Trauma 2001 Sep;51(3):481-9.

88. Thiruppathy SP, Muthukumar N. Mild head injury: revisited. Acta Neurochir (Wien) 2004 Oct; 146(10):1075-82; discussion 1082-3.

89. Yates PJ, Williams WH, Harris A, Round A, Jenkins R.An epidemiological study of head injuries in a UK population attending an emergency department. J Neurol Neurosurg Psychiatry 2006 May;77(5):699-701.

90. Marshall LF, Marshall SB, Klauber MR, et al. A new classification of head injury based on computerized tomography. J Neurosurg 1991;75(Suppl):S14-S20.

91. ValadKa AB, Narayan RK. Emergency room management of the head injured patient. In: Narayan RK, Wilberger JE, Povlishock JT (eds). Neurotrauma. New York: McGraw-Hill, 1996, p.119-135 cap8.

92. Chesnut RM. Treating raised intracranial pressure in head injury. In: Narayan RK, Wilberger JE, Povlishock JT (eds). Neurotrauma. New York: McGraw-Hill 1996; p.445-469 cap32.

93. Ambrose PG, Owens RC, Quintiliani R, et al. Antibiotic use in the critical care unit. Crit Care Clin 1998; 14:283-308. 
94. Yamaushi NI, Munhóz CHF, Ferreira AMTGB. Procedimentos invasivos. In:Fernandes AT, Fernandes MOV, Ribeiro Filho N (eds). Infecção hospitalar e suas interfaces na área da saúde. São Paulo: Editora Atheneu 2000; V2:957-997 cap52.

95. Greenberg SB, Atmar RL. Infectious complications after head injury. In: Narayan RK, Wilberger JE, Povlishock JT (eds). Neurotrauma. New York: McGraw-Hill, 1996, p.703-722 cap48.

96. Park P, Garton HJL, Kocan MJ, Thompson BG. Risk of infection with prolonged ventricular catheterization. Neurosurgery 2004 sept; 55:594:601.

97. Ribeiro Filho N. Agentes antimicrobianos. In:Fernandes AT, Fernandes MOV, Ribeiro Filho N (eds). Infecção hospitalar e suas interfaces na área da saúde, São Paulo: Editora Atheneu 2000; V2:1485-1534 cap83.

98. Clark WC, Muhlbauer MS, Lowrey R, et al. Complications of intracranial pressure monitoring in trauma patients. Neurosugery 1989. 25:20-24. 